Hooll

hjuoz.uoz.edu.krd p-ISSN: 2664-4673 e-ISSN: $2664-468$
كَوْارا زانستيّن مروّايهتى يا زانكوّيا زاخوّ

مجلة العلوم الانسانية لجامعة زاخو

Humanities Journal of University of Zakho (HJUOZ)

Vol. 9, No. 3, pp. 647-663, Sept..-2021.

\title{
إتجاهات عينة من طلبة كلية الإدارة و الاقتصاد نحو قيمة المال وعلاقتها ببعض المتغيرات نصرالدين ابراهيم محمد
}

قسم علم النفس العام، فاكولتى التربية، جامعة زاخو، اقليم كردستان - العراق.

https://doi.org/10.26436/hjuoz.2021.9.3.713 2021/09 2021/09 تاريخ القبول

تاريخ الاستلام: 2021/06

الملخص:

يهدف البحث الحالي التعرف على إتجاهات عينة من طلبة كلية الإدارة و الاقتصاد بجامعة زاخو نحو قيمة المال والتعرف على الفروق تبعاً لمتغيرات (الجنس، المرحلة، مهنة الأب و الأم، مستوى الثقافي لوالديهم، و الوضع الاقصادي للعائلة، موقف الوالدين الطلبة من الحياة، و محل السكن)، وتألفت عينة البحث من (122) طالب و طالبة تم اختيار العينة بطريقة عشوائية من المجتمع الأصلي و بنسبة (74\%)، و لهذا الغرض إستخدم الباحث مقياساً جاهزاً والمؤلف من (30) فقرة و (7) مجالات(زيدان، 2008)، وتم استخراج الخصائص السيكومترية، ولغرض معالجة البيانات المستخرجة، تم إستخدام الحقيبة الإحصائية للعلوم الإجتماعية (SPSS)، وتبين وجود مستوى سلبي من إتجامات طلبة عينة البحث نحو قيمة المال، مع وجود فروق ذات دلالة إحصائية بين إتجاماتهم وفقا لمتغيرالجنس، ولصالح الطالبات، و عدم وجود فروق ذات دلالة إحصائية بين إتجاهاتهم وفقاً لمتغيرات الأخرى. الكلمات الدالة: اتجاهات، طلبة الجامعة، القيمة، المال.

خلال المؤسسات التعليمية أن يكتسبها الطلاب من خلال المنهج الدراسي و تزويدهم بمعارف عن أنفسهم و البيئة التي يعيشون فيها، و ذلك يعني أن المعرفة تدخل في نسيج القيم، ما يسمى بالتربية القيمية (سعيد، 2008: 23، البيلاوي، 2006: 56، عيسان و آخرون، 2007: 137)، و التربية في خلاصتها النهائية مجهوداً قيمياً مخططاً يستهدف تحليل قيم المجتمع و غرسها في الأفراد (عزيز، 2007:

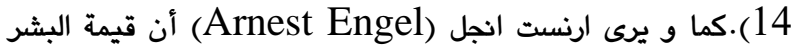
تعادل قيمة المال التي أنفقها الوالدان على الفرد من وقت الحمل حتى

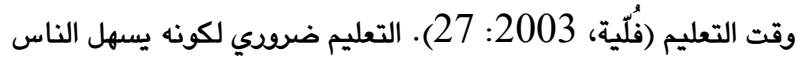
في التعبير عن ثقافتهم، إعتماداً على المال الذي يخصصه كل فرد لتلبية و إثباع حاجاته الأساسية في الحياة ألتي هي قيمة بذاتها، و يسمى هذا الاتجاه الحديث توجه إنساني (a people-oriented)، و ألتي

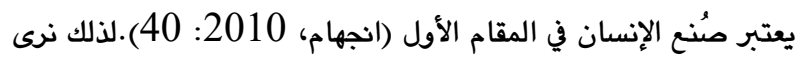
المال الذي يمتلكها و يستخدمها الإنسان لتسهيل وإستجابة لرغباته الحياتيه، وعملية الإنتاج يعتبر ركيزة أساسية للتطور الإجتماعي و Pearce and Robinson, (المادي(مشورب، 2002: 92 :2005). بينت نتائج دراسات انجلهارت و مختصيين أمريكيين الآخرين لدول عديدة في العالم أن التطور و التقدم في المجتمعات مختلفة لهم علاقة وطيدة بالتغيرات في القيم الاجتماعية و اتجاهات الثقافية في المجتمع، و منها قيم الاقتصادية(أله (Moreno, 2008 :

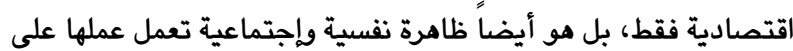

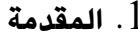

1 - 1 - 1 مشكلة البحث: تكمن مشكلة البحث في أهمية اتجاهات الطلبة نحو المنهج الدراسي و موادهم العلمية في النجاح و إنجازهم الدراسى، و خاصة أن قسم علوم المصرفية والمالية يتضمن (5) من المواد ألتي يوجد في عنوانها إسم المال وكذلك المحتوى المواد الدراسية كثير من المصطلحات في هذا الإطار و هي إدارة المؤسسات المالية و المصرفية، و نقود و بنوك، و الرياضيات المالية، و المالية العامة، و قراءات مالية و مصرفية، في مرحلتي الأولى والثانية فقط، كما والتوجه العام نحو المال أزداد بعد ازدياد متطلبات الحياة و طموحات الناس. كما و أن للأزمة المالية التي عان منها شعب كوردستان في سنوات أخيرة بسبب العقويات المفروضة من قبل الحكومة المركزية دافع آخر للبحث و التقصي في الموضوع الحالي،ويمكن تحديد مشكلة البحث بالسؤال الآتي:ما مو اتجاه هذه العينة من الطلبة نحوقيمة المال، كأحدى القيم الاقتصادية الضرورية

$$
\text { في الحياة في ضوء بعض المتغيرات؟ }
$$

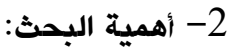

التعليم هو المدخل الطبيعي لبناء الإنسان، و هو القوة المؤثرة في التنمية الاقتصادية، و تطوير الإتجاهات الفكرية و الإجتماعية، و قواعد المجتمع والقيمية، و إثباع حاجات الأفراد و مطالبهم الشخصية (فُلّية، وتهات 2003: 391، القريشي، 2011: 245)، و بما أن الشخصية عبارة عن مجموعة من العوامل و منها القيم، والتي تفرز الإتجاهات، حيث تأتي الإتجاهات رتبة بعد القيم، وللاتجاهات و القيم أهداف تسعى التربية من 
الحياة بقسميها المادي و الروحي بإعتبارما تمثل شطري ضرورة الإنسان في خلقته و تكوينه، و لايستقيم طريقة كما لا تستقيم حياته

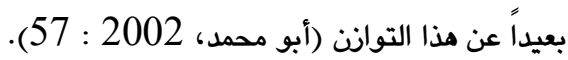

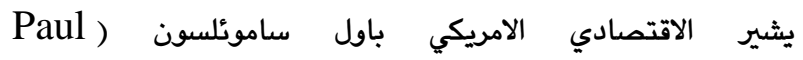
(Samuelson في مجال تطوير الإقتصادي (النسور، 2015: 24). يرى برتراند راسل

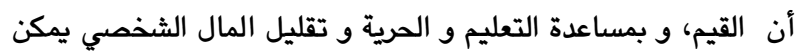

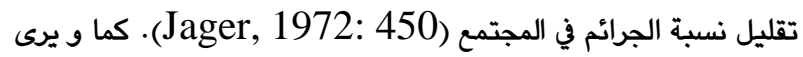
الآخرون من أمثال بارسونز (F. Parsons) و وليامسون أهمية القيم و الإتجاهات في نجاح الفرد المهنية، (Williamson) لذلك يؤكدون على أهمية اسنادها إلى الأسس العلمية في الجامعات، بالنظر لأهميتها التربوية و النفسية و الإجتماعية و الإقتصادية، مؤكداً أهمية حرية الفرد في إختيار المهنة أو نوع التعليم الذي يناسبه تلبية لحاجات المجتمع من القوى العاملة المدربة و المؤملة (القاسم، 2001:

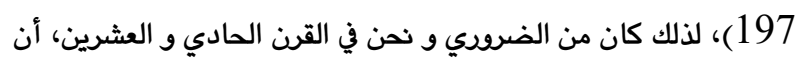
نربط القيم المادية و القيم المعنوية في عقول الناشئة و في منهج التعليم

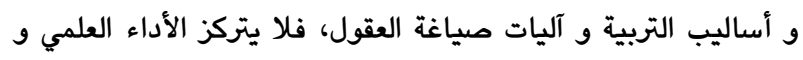
التربوي على الجانب المادي فقط، و إنما لابد من تكامل الرؤية بين الجانبين حتى نتلاثي انشطار الذات. (أبو محمد، 2002 : 58). كما توصلت العالمة النفسية الأمريكية (Becca Lery) من جامعة(Yale) في دراساتها لسنوات متتالية إلى أن إتجاهات الفرد تؤثر في قدرات المرء الجسدية وصحته العقلية وعمره وإحساساته وتقديره لذاته، ويالتالي إتخاذه للقرارات السليمة التي تخصه وتخص الآخرين (Winerman, 2009 : 45). أمريكية بأن هناك علاقة بين حياة إجتماعية ناجحة و قيم الأفراد. (Ingelhart, 2003, 23). لذلك نرى توصي الدراسات النفسية و الإجتماعية في إقليم كوردستان على ضرورة التأكيد على القيم التربوية و النفسية لدى الطلبة لتنمية روح الإبتكار و الإبداع لديهم من خلال المنامج الدراسية من قبل وذارتي التربية و التعليم العالي و البحث العلمي في الإقليم، و ذلك للتشجيع على الإبداع و الإبتعاد عن التقليد

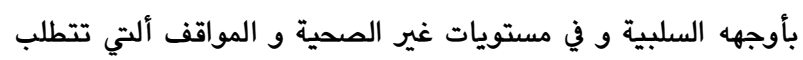
إتخاذ القرارات، بإتخاذ مواقف سلبية عدائية تجاه أي شىء من شأنه أن يتعارض مع عالمهم الداخلي و الحياة الواقعي و ألتي تتطلب تلبية

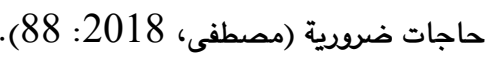
وفي ضوء ما قدم سابقاً، و نظراً لعدم وجود بحث تناول إتجاهات طلبة الجامعة نحو قيمة المال في إقليم كوردستان - على حد علم الباحثلذا جاءت فكرة البحث الحالي الذي سيحاول الباحث- التعرف على إتجاهاتهم في هذا الخصوص لإعطاء صورة واضحة للتدريسيين و الجهات المعنية في القسم و الجامعة و الإستفادة منها في تحقيق أهداف التعليم الجامعي في هذه المرحلة ليواكب مع تطورات العلمية و التقنية
المستويين الفردي و الجماعي، بالإعتماد على الوجدان و الإدراك و

$$
\text { النزوع · (زيدان،2008: } 7 \text { ). }
$$

بالرغم من أن البعض يرون حب المال كجزء من مكونات مرض الحسد و له أضراره جنباً الى جنب التكبر و التعصب و العدوان ما يؤدي إلى يلى الآلام و المشكلات للإنسان (تووسى، 1388: 489)، إلّا نرى في الامثال و الحكم الشعوب المختلفة و منها الشعب الكوردي أكثر من (30) مثالاً حول المال (رخزادى، : 353، سندى، الأل 2010: 897). أن كلام جميل و ذو معنى عميق لبارزانى الخالد، القائد الاسطورى الكوردى، حينما يقول "من الواجب أن نستغل مالنا و حياتنا و عقلنا و علمنا و كل ما لدينا من أجل الشعب، ليحصل على الحرية" (عةبدولَّا، 2018: 6)، و يؤكد على هذه الفكرة السياسيون الكورد، عندما يرون

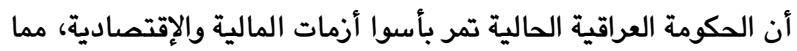
أدى إلى كثير من المشاكل و منها البطالة، و ألتي زادت في الآونة الأخيرة، و تسببت كثير من المعانات و منها الحروب، و لذلك الطريق الوحيد للتخلص من هذه الأزمات هي تقوية الجانب الإقتصادي في البلد، و لهذه الطريق أهمية قصوى، و يجب أن تكون من أوليات الحكومات المقبلة (حسين،2018 : ب.ص.)، و مذا المؤشرات خير دليل على أهمية المال في المجال السياسى و تلبية مبادىء و قيّم الديمقراطية و كسب الرفاهية للشعوب. يرى جتشير و آخرون (Gachter et al., 2011) قيمة رأس المال المالي قريب من مفهوم رأس المال الإجتماعي حيث يمكن أن يتولد في المستقبل ويستخدم لشراء الأثياء مثل الدعم الإجتماعي أو المساعدة، و ذلك من خلال شعور مشترك بهوية تبادل الإمتيازات و الإنتماء و التضامن و قواعد التعاون المحفزة على الشعور بالإلتزام بمساعدة الآخرين و التأكد أن مثل هذه المساعدة سوف تسترد في يوماً ما (العبادي، 2014 : 177). لذلك نرى أن مدارس السلوكية و الفرويدية و المعرفية يؤكدون على أهمية تلبية المال و الثروة في حياة الفرد و سيادته في البيئة و التكيف معها من خلال إستخدام العقل (حوسيَن، 2017: 168). لأن التناقض بين فكره و بين قوله و عمله، يؤدي إلى الصراع القيمي و حدوث مشكلة بين الإتجاه نحو قيمه المختلفة مما يؤدي بدوره إلى الصراع بين القيم الروحية و المادية، و بين قيم الايثار

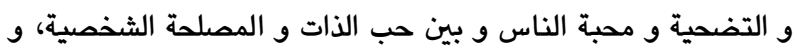
بالتالي نحو الإزدواجية في البناء الشخصي المؤدية إلى مشكلات النفسية كالقلق و الحيرة و عدم تقدير الذات و فقدان الإتزان و السعادة، و ظهور

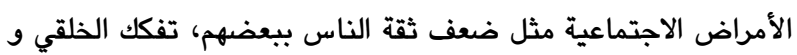
العلاقات الأسرية و الإجتماعية (الجلاد، 2005: 99). هذا ما أكده أدلر في كتابه (فهم طبيعة الإنسان)، عندما يريد أن يربط بين جمع المال و النقود بالطمع و الحرص، وتنبيه الإنسان من مساوئه و عواقبه

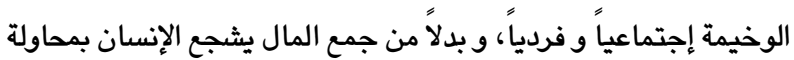
تكيفه مع نفسه و المجتمع (ئادلةر، 2018: 314).التوانن بين قيم 
خلال ما تحصل عليه هؤلاء الطلبة من درجات الحاصلة على مقياس المعتمد في البحث الحالي. 5-2-2-القيمة(Value):

تعريف ف.كلوكهوهن و اس.كلوكهوهن (1967) للقيم هي التمثيلات المعرفية لدى الفرد أو مفهوم شبه صريح أو ضمني يميز بها الفرد أو جماعة وتؤثر في عملية الاختيار من بين الأشكال والأهداف و الوسائل المستخدمة من قبله للعمل و الوصول إلى غاية العمل ، ويعتبر أساس بين حاجاته و دوافعه و ميوله في الحياة اليومية . ) : Rokeach, 1979 .(Леденоц, 2007:54 “Гаврилова, 2003: 6 “322

تعريف ئيفستسوفا:"الأجزاء التي تنظم السلوك التربوي وتوجههم نحو العلاقات المتبادلة بين المدرس والطلبة"(:

التعريف النظري للقيم الغائية للبحث الحالي: هي مجموعة من النسق أو الإتجاهات و المعتقدات الأساسية ألتي يكتسبها الفرد من خلال تفاعله النشط مع البيئة الاجتماعية المحيطة به ليتعامل بموجبها في حياته العلمية والعملية و التربوية. التعريف الإجرائي للقيم في البحث الحالي: مجموعة من المبادئ والقواعد والمثل العليا يتمثلها الطلاب في الجامعة، ويعتمدون عليها في إنتقاء سلوكهم وألتي يحصلون عليها الطلاب من خلال درجات الحاصلة على مقياس التوجه نحو قيمة المال المعتمد في البحث الحالي. (capital):-3-5 تعريف جرينكيرك و اوازافا-راي: النقود و الثروة التي استثمرت في مجالات مختلفة. ) Gwynkirk and Okazawa-Ray, (2004: 375

تعريف برائولت و آخرن: إنتاج طويل الدوام و الغالي ألتي يمكن الإستفادة منها لعدة سنوات (204 : Perrault, et al, 2008 ( تعريف العلي: المال هو مجموعة من مصادر لتمويل المنشأة. (العلي، . 2017

تعريف الشمري، و آخرون: المال هو المتغير الذي يستخدم لمرة واحدة في عملية إنتاجية معينة. (الشمري، و آخرون، 1999 : 22). تعريف كارل ماركس: المال هو عمل مجسم أو عمل مدخر (بارودي، (45:2012

6- أدبيات البحث و خلفية النظرية:

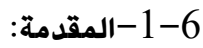

من خلال مراجعة الأدب التربوي يتبين مدى إندماج و تلاحم كلمتي الإتجاه و القيم فهما تستخدمان عنوان في العديد من المواقف التعلمية

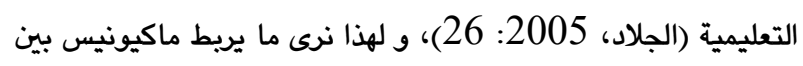

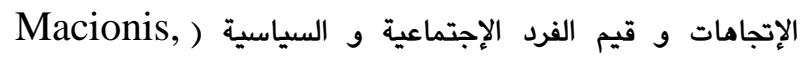
2006, 210 و و بما أن الإتجاه هو مجموعة من الإستجابات السلبية
في العالم بصورة عامة و كوردستان-العراق بصورة خاصة في مجال علم النفس حيث تطور مذا العلم في الآونة الأخيرة .

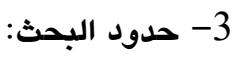

يقتصر حدود البحث الحالي على جميع طلبة قسم علوم المصرفية و المالية لكلية الإدارة و الاقتصاد في جامعة زاخو للعام الدراسي (2018-2017)

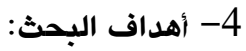

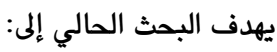
أولاً: التعرف على إتجاهات عينة من طلبة الجامعة نحو قيمة المال

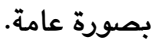
ثانياً:التعرف على دلالة الفروق الإحصــــائية في إتجاه عينة من طلبة

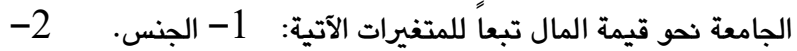

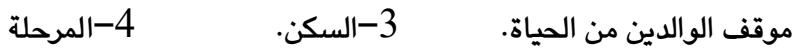

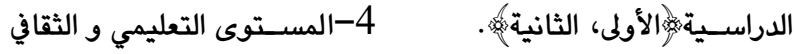

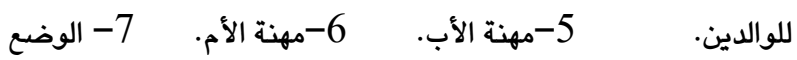

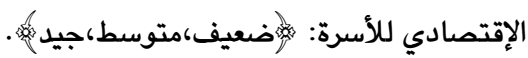

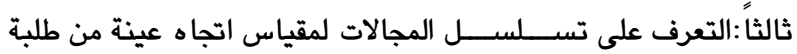

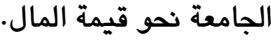
5- تحديد المصطلحات:

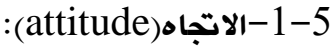

- تعريف وست و تورنر: هي علاقة بين الفرد و الآخرين ( West and .(Turner,2004, 339 -تعريف مييرز: رد فعل تقويمي سلبياً ام ايجابياً نحو شيء أو شخص المنعكسة في أفكار أو أحاسيس الفرد أو أفعاله ) Meyers, 2005

-تعريف جونز وجورج: مجموعة من الأحاسيس و المعتقدات. .(Jones and George, 2006, 87) تعريف عبدالحي: تكرار الحدث بإتساق يتولد عنه حمل ظاهرة ما على أن تأخذ نمطاً معيناً في تغيرها من حالة لأخرى (عبدالحي، 2007:

-تعريف كولمان: نمط ثابت من إستجابة تقويمية نحو شخص أو

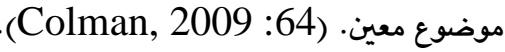
التعريف النظري للإتجاه في البحث الحالي: هي مجموعة من الأفكار و المعتقدات ألتي يكتسبها الفرد من خلال تفاعلاته الحياتية مع البيئة الإنسانية والإجتماعية المحيطة به نحو الأشياء أو أشخاص أو مواضيع

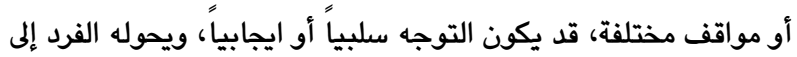

سلوكيات يتفاعل بموجبها في المواقف الحياتية العامة و التعليمية. التعريف الإجرائي للإتجاه في البحث الحالي: هو توجه الذي يمثله

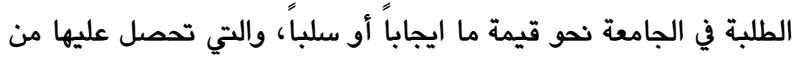


المتعلقة بالإتجاهات و القيم، كما يعتقد كراثول و رفيقاه (1985) ضمن تصنيف مذا الأهداف في مستويات مختلفة (الجلاد، 2005:

6-2-نظريات فسرت الإتجاهات و القيم: مناك نظريات عديدة فسرت الإتجاهات و القيم على أسس ألتي تعتمد عليها كل نظرية وهي: نظرية الإشراط الإجرائي ل سكنر: ان تفسير هذه النظرية لتكوين النيات

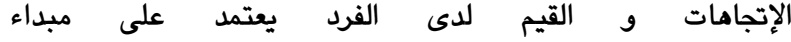
التعزيز(reinforcement)، أي ان إستجابة الكائن الحي الذي يتم تعزيزه، يزداد إحتمال حدوثها و تكرارها، وهذا ما يحدث في تكوين الإتجاهات لديه (العثمان، 2011: 38 38). نظرية باندورا وولتر: تفسر النظرية عملية تكوين الإتجاه و القيم من خلال عملية التعلم بالملاحظة، حيث عند الإنسان ميل فطري

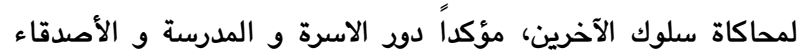

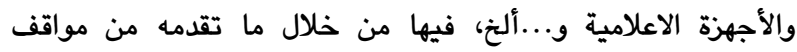

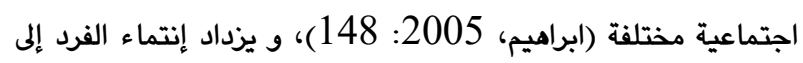

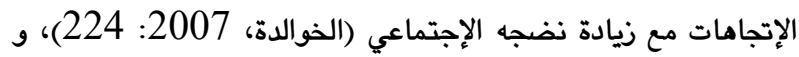

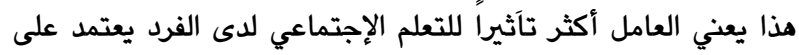

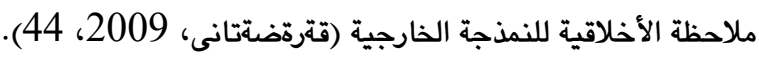
نظرية كولبرج: يرى (Kohlberg, 1973) أن الفرد يمر بمستويات مختلفة تدريجياً، و يتأثر بالقواعد الإجتماعية و تبني ثقافة الخير و الشر، عن طريق التفكير في القيم و مبادىء الإنسانية، كما و عن طريق عما يترتب على سلوكه من نتائج مادية و تقديره للقيم في ذاتها (عبدالعزيز، 2006: 250). نظرية المعرفية: حسب هذه النظرية أن إتجاهات السلوك بين الجماعات ترجع إلى العمليات المعرفية ألتي تسبق تكوين وجهة نظر التران إحدى الجماعات في غيرها من الجماعات. تبدأ العمليات المعرفية المرتبطة بالإتجاهات و القيم بتصنيف الآخر و عن طريق ما ينتشر بين

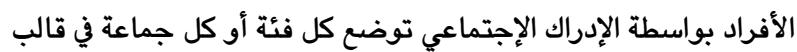
نمطي تعرف به في المجتمع و يتم التعامل بين أفرادها من خلالها (ابراهيم، 2005: 147). يؤكد ميلتون روكيش (M. Rokeach) أحد رواد هذه المدرسة على أنه لتفهم شخصية الفرد يجب أن نكون

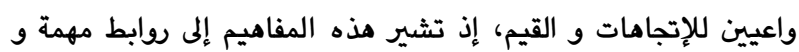

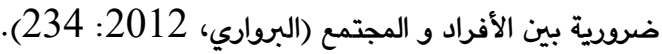
نظرية التنافر المعرفي: أن التفاعل الإجتماعي بحسب فستنجر يؤدي التراري،

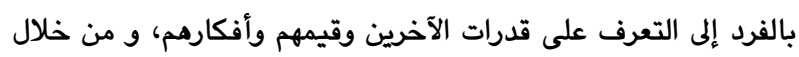

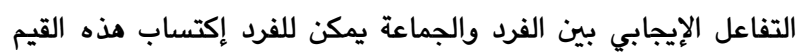
والأفكار و الإتجاهات مما يشير إلى إنتمائه لهم و تفترض عملية المقارنة الإجتماعية ضرورة وجود القدرة على التشابه بين الفرد و بين من يقان نفسه بهم(بكر،2013: (77).
و الإيجابية لموقف محدد أو موضوع معين، فإذا اتيحت الفرص لتكرار

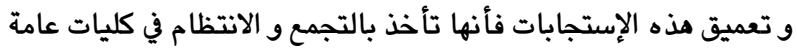

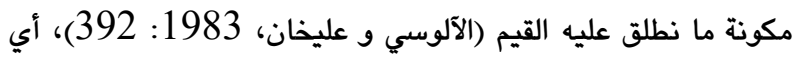
أن القيمة هي المكونة الأساسية للإتجاه و تمثل منظومة من الإتجاهات، و قد تمثل القيمة الواحدة إتجاهات متعددة و تختلف من فرد إلى آخر حسب تفسيره للقيمة و الإتجاهات فإنها تأتي رتبة بعد القيم، حيث أن

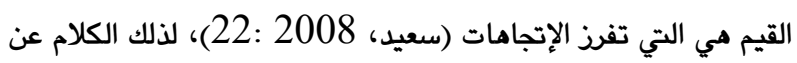
جوانب مختلفة منهم في مواضيع المفهوم، الوظيفة، العوامل المؤثرة في

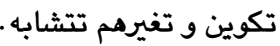

إستخدم بعض المختصيين مفهوم الإتجاه في مخططاتهم النموذجية مرادف لمفاهيم الفكر، المعتقدات، التذكر، الإستدعاء، التصور، التعرُف (4stington, Harris and Olson,1990 : 418) جانب آخر قد أقرّ أغلب المفكرين منذ القدم، و منهم مثلاً (هوبز، مل، سارتر...الخ) عن وجود إختلاف بين المكونين الفكريين: الحرية والفوضى أو الإباحية، ويوضحون أن الحرية نظام حياتي يدعو إلى

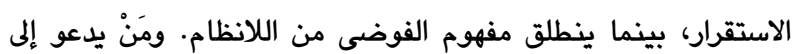

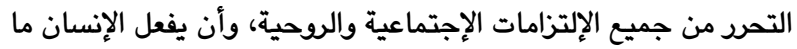
يشاء دون الإعتراف بالقوانين، والسماح للآخرين بإطلاق نزواتهم، فمثل

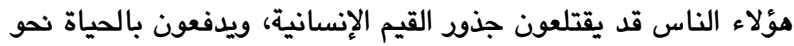
الهاوية(الطعيمات، 2001 : 29)، كما و أن نيتشة يرى أن الإنسان بمجرد القيام ضد القوى الخارجية قادر أن يشجع نفسه للرجوع إلى قواه الداخلية و الذاتية، كمصدر لقيم الأخلاقية الحقيقية بل جميع القيم

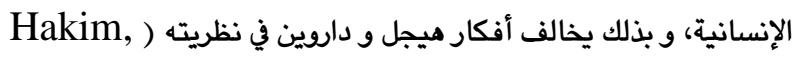
.2006: 474 من أبرز العوامل المؤثرة في تكوين الإتجاهات و القيم هي عامل الوراثة،

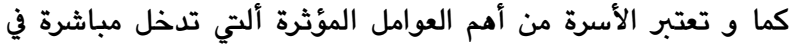
تكوين الإتجاهات و القيم لدى الإنسان منذ الطفولة نحو موضوعات الترات

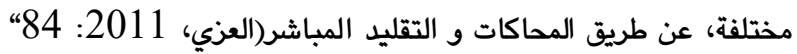
Matthews, A., ( نجاتى، 1389: 155). يرى ماتيوس

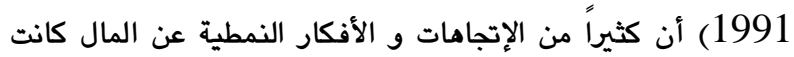

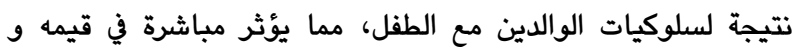
معتقداته، حتى بعد مرحلة الطفولة (زيدان، 2008: 152). أكد كل

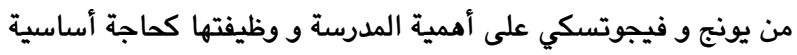
للفرد (محمد، 2004: 4 )، في تكوين الإتجاهات و القيم لدى الأفراد، بينما يشير الآخرين إلى المجتمع المحلي بقيمه له تاثير مهم في عملية تكوين و تغيير الإتجاهات إزاء مواضيع و مواقف، و ذلك عن طريق الكيق وسائل مختلفة منها الإعلام، و منها الراديو و التلفزة و الجرائد و الصدف مادف

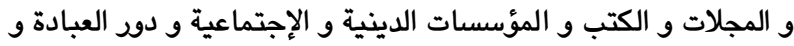

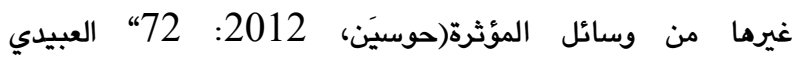
وولي،2009: 314)، نرى هذه الحقيقة عندما نقوم بتقييم الأهداف 
دوراً أساسياً في عملية صُنع القرار سواء الإقتصادي أو السياسي أو

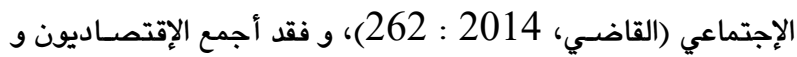
في مقدمتهم آدام سميث على أن رأس المال البشـري جزاً أسـاسـياً من

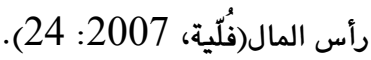

نظرية بوتنام: يؤكد بوتنام في نظريته في مجال رأس مال الإجتماعي على أهمية أصدقاء و زملاء و الجيرة في العلاقات الإجتماعية، و تلبية

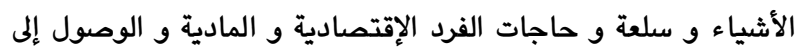

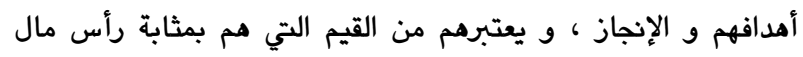

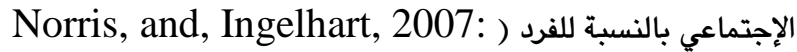

نظرية رأس المال المادي التقليدي(الكلاســـيكية): أكد على أهمية رأس المال المادي كعنصر من عناصر النمو الإقتصادي، إممالاً

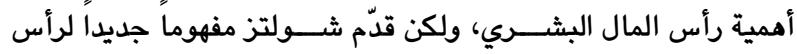

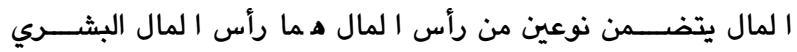

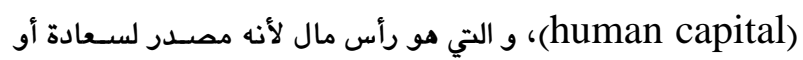

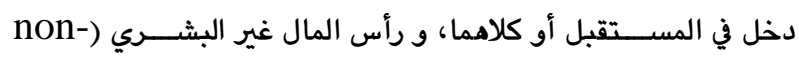

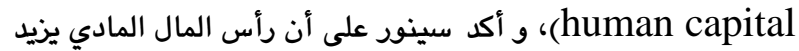

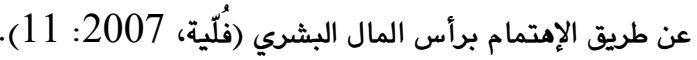

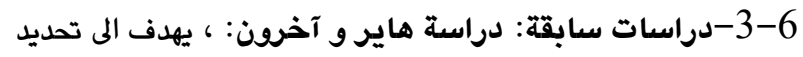

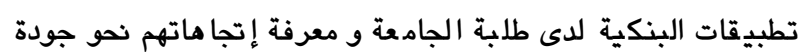

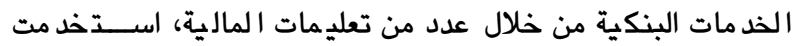
المقابلة و استبيان مكون من 30 فقرة و القاء محاضرات في التعليمات

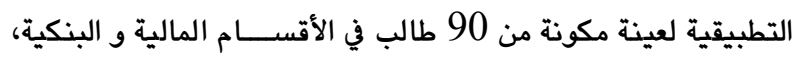
بدون ذكر النتائج (Hair, 2006: 459). 7- الإجراءات المنهجية للبحث: 7-1-منهجية البحث واجراءاته: اعتمد الباحث المنهج الوصفي البهات

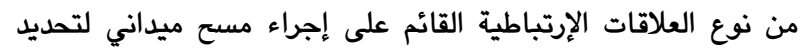
مجتمع البحث واسلوب اختيار العينة والأداة المستخدمة في قياس الإنيال المتغير الذي تناوله البحث وطريقة جمع البيانات و الوسائل الإحصائية المستخدمة في معالجة البيانات الواردة في البحث وكما يلي:

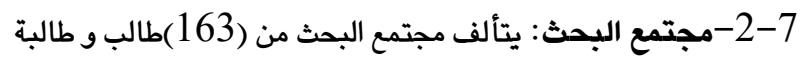
في مرحلتي الاولى (89) و الثانية (74) من قسم العلوم البنكية والمصرفية في كلية الإدارة والاقتصاد بجامعة زاخو، و مرحلتي الثالثة و الرابعة لا توجد لحد الآن. 7-7-8 و الرابعة لا توجد البحث: تتألف عينة البحث الحالي من (122) طالب و طالبة، أي بنسبة (74.)، و لغرض توخي الدقة تم اختيارهم بطريقة عشوائية طبقية، كما هو موضح في جدول (1).
نظرية الوظيفية للإتجاه: يقول كل من كاتز (Katz) و ستوتلاند

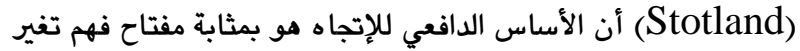
الإتجاه ومقاومتها للتغيير. كما أن العوامل الاتصالية و الموقفية الإتاه

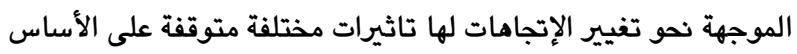
الدافعي لهم، ومن خلال تعبير الفرد عن ذاته بالإتجاهات فإنه يستمر الإثباع عندما تكون هذه الإتجاهات متسقة مع مفهومه عن ذاته وقيمه الشخصية، ومن وجهة نظر الوظيفيين أن السلوك المنحرفة يعتبر سلبية

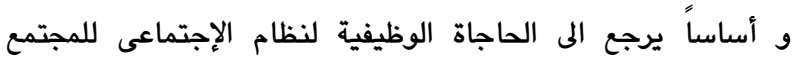

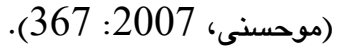
نظرية فروم: يرى فروم أن خوف الإنسان أو التنبؤ بالخطر من

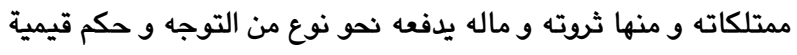
النرجسية المنحرف، كردود فعل إكتئابية لملكيته الخاصة لهذا التهديد

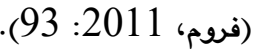
نظرية فرويد: وفقاً للنظرية قسوة الأنا الأعلى و شدة صرامتها تحيل

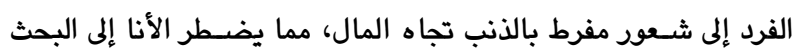
عن رشــوة للأنا الأعلى بغية تقليل الإحسـاس بالذنب، فتنكر الأنا كل بل الـاهل

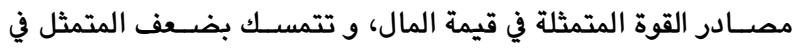
الديون و إضاعة المال، كمحاولة لإستمالة الأنا الأعلى. كما و أن لعامل

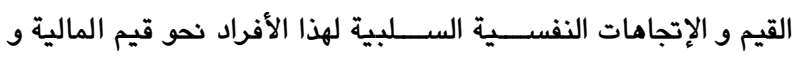

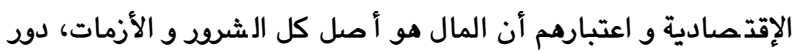

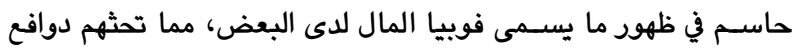
لاشعورية على التبذير و إضاعة المال بأي شكل و بأي طريقة (زيدان، 178: 2008

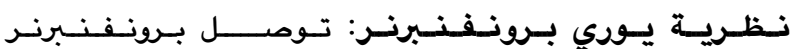

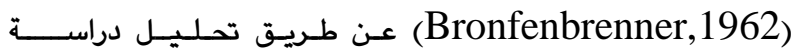
النموالأخلاقي والقيم الإجت ماءية بين الثقا فات المختلفة الى القواعد الفعلية التى تحكم السلوك (الضبط الداخلي والضبط الخارجي) تكمن في أعماق الأنماط الثقافية، لأذها ترتبط بالوظائف التركيبية للقيم كالعدل والتعاون والحرية (فتحي، 1983 : 152). نظرية فيشر: أدخل ايرفين فيشر(Irving Fisher) من المهتمين ولهيك بالتربية بعض العناصـر ضــمن عناصـر رأس المال و منهم العنصـر الإنساني، و يعتقد بأن إذا كان رأس المال هو الرصيد الذي يؤدي إلى مزيد من الدخل بمضـــي الوقت، فإن الأموال ألتي توضـــع في التعليم توضــع للحصــول على مزيد من الدخل ســـاء من وجهة نظر الفرد أو

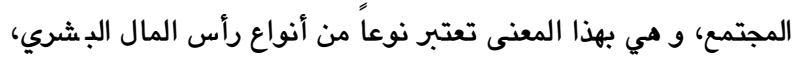

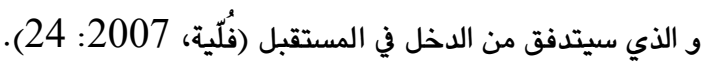
نظرية آدم سميث: يرى سميث قيم الفرد مرتبطة بمفاهيمنا التربوية و السـياسـية و الأخلاقية و الديمقراطية و التاريخية و الوطنيةو تلعب 


\begin{tabular}{|c|c|c|c|c|c|}
\hline 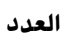 & مهنة الاب & 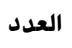 & المستوى الاقتصادي & 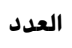 & الجنس \\
\hline 43 & لا يعمل & 28 & ضعيف & 63 & ذكر \\
\hline 9 & 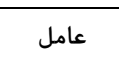 & 90 & متوسط & 59 & أنثى \\
\hline 70 & موظف & 4 & جيد & العدد & المرحلة \\
\hline العدد & مهنة الام & العدد & المستوى الثقا في & 76 & اولى \\
\hline 113 & لا تعمل & 34 & أقل من الثانوي & 46 & ثانية \\
\hline 3 & عاملة & 3 & معهد & العدد & محل السكن \\
\hline 6 & موظفة & 38 & جامعة & 22 & قرية \\
\hline 122 & المجموع & 47 & دراسات عليا & 100 & مدينة \\
\hline
\end{tabular}

النتائج بمصداقية (66 :Dunn, 2001)، ولإيجاد ثبات المقياس استفاد الباحث من طريقة إعادة تطبيق المقياس على نفس الأفراد بعد مرود اسبوعين تقريباً من التطبيق الأول،و بإستخدام معامل الإرتباط بيرسون في المعالجة الاحصائية، و تبين أن قيمة الإرتباط بين نتائج التطبيق الأول و الثاني تساوي (0.79) وهو معامل ثبات يمكن

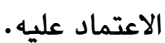
7-5-تطبيق المقياس: بعد الإنتهاء من إجراءات الصدق و الثبات

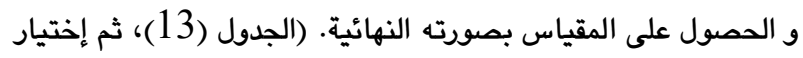
عينة مناسبة غير تلك المشمولين بعينة الثبات، و طبقوا عليهم

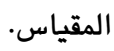
7-6-تصديح المقياس: لأن للمقياس خمس بدائل و هي (الرقم

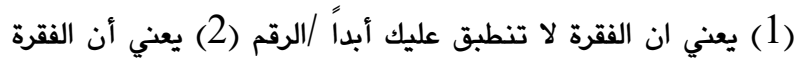

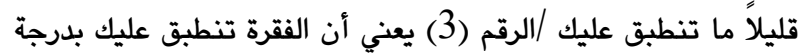

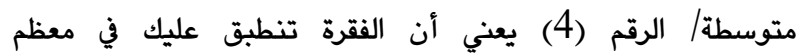

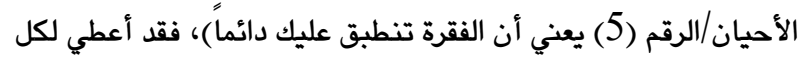

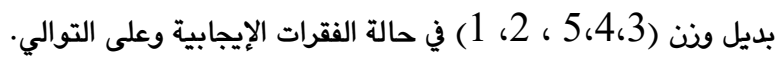
7-7-7الوسائل الإحصائية: تم معالجة البيانات بواسطة برامج .(SPSS)g (Excel)

\section{8-عرض النتائج و مناقشتها}

بعد إستخدام التحليل الإحصائي تبين وحسب أهداف البحث ما يلي: 8-1-الهدف الأول: التعرف على آراء عينة من طلبة الجامعة حول

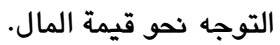
للتاكد من هذا الهدف تم استخدام المتوسط الحسابي، والإنحراف

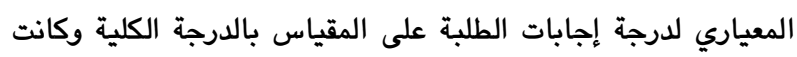

النتيجة، كما هو موضح في الجدول(2).

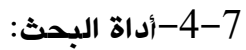
7-4-1-وصف الأداة: من أجل تحقيق أهداف البحث إستخدم الباحث استبيان جاهز مكون من (30) فقرة في سبع مجالات (مجال الخير، مجال الشر، مجال الإنجازات، مجال احترام وتقدير الذات، مجال الميزانية، مجال الحرية، مجال القوة)، من إعداد (زيدان، 2008: 207). كما وقام بالمقابلة مع (42) طالب و طالبة من طلبة القسم المذكور و ملىء استبيان استطلاعي مكون من سؤالين مفتوحين: كطالب في قسم علوم المصرفية و المالية و التي يدرس عديد من المواد الدراسية تحت عنوان و مصطلح (المالية و المصرفية)، هل برأيك المال شيىء جيد أم لا ، و لماذا؟. 7-4-2-2 شدق المقياس: لأجل التحقق من صدق المقياس تم عرضه على مجموعة من الخبراء والمحكمين في مجال التربية وعلم النفس،وطلب منهم الحكم على مدى صلاحية فقرات المقياس، وفي ضوء ملاحظاتهم اعيد صياغة بعض الفقرات، و م استبعاد (5) فقرات،

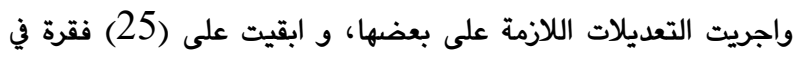

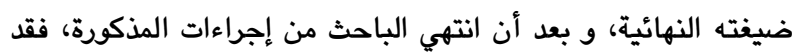
قام بوضع مقدمة تشرح هدف البحث و تعليمات كيفية الإجابة عن الاستبيان، كما و قام الباحث بترجمة الاستبيان إلى اللغة الكوردية و عرضه على مجموعة من المحكمين في اللغة الكوردية و التربية و علم النفس، و طلب منهم قراءة الفقرات و إجراء التعديلات اللازمة، و كان لمقترحاتهم أثر إيجابي في صياغة الاستبيان باللغة الكوردية صدقاً

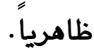
7-4-3-4

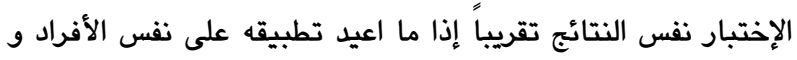

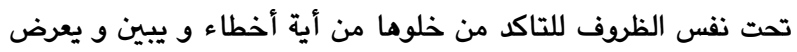

الجدول(2)المتوسط الحسابي والإنحراف المعياري لدرجة إجابات الطلبة على المقياس بالدرجة الكلية

\begin{tabular}{|c|c|c|c|c|c|c|c|}
\hline مستوى الدلالة عند & لدرجة الحرية & القيمة التائية & القيمة التائية & المتوسط النظري & المعياري الإنـراف & الحسوسابي & العدد \\
\hline دالة & 121 & 1.96 & 0.603 & 75 & 14.564 & 74.204 & 122 \\
\hline
\end{tabular}


التائية المحسوبة تساوي (0.603) وهي أقل من القيمة التائية

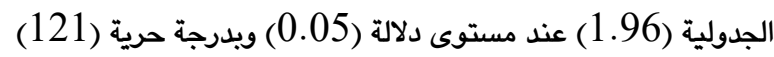
وتشير هذه النتيجة إلى وجود مستوى سلبي من إتجاه نحو قيمة

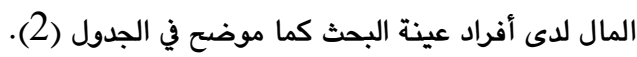

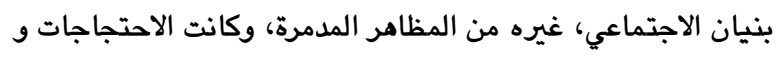

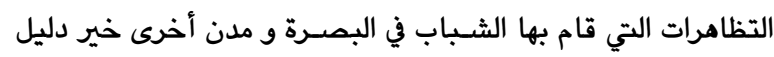

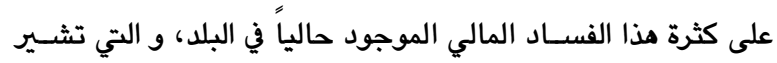

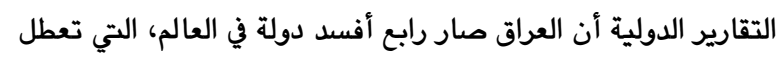

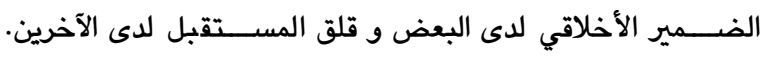

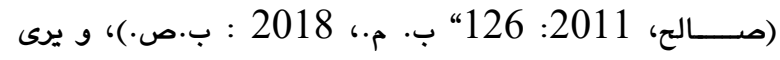
زرادشـــت أن مهادنة المذنبين و المفســدين جرم عظيم، و القانون

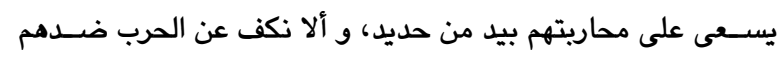

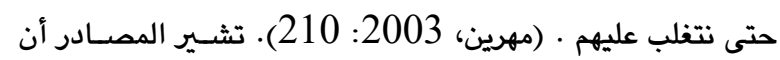

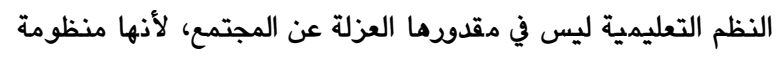

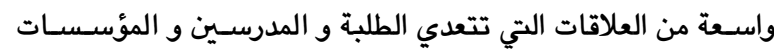

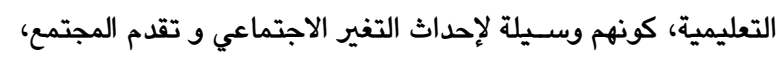

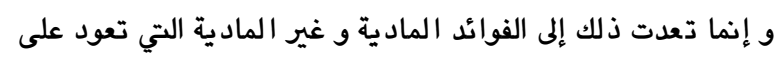

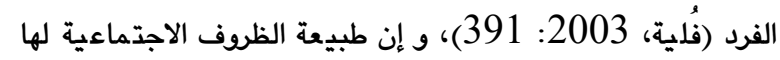

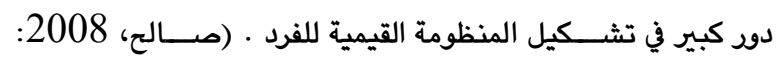

8-2-الهدف الثاني: التعرف على الفرق الدال احصائياً بين

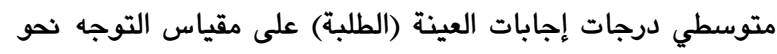

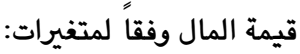
-1-2-8 - الجنس: للتحقق من ذلك تم استخراج المتوسط الحسابي والإنحراف المعياري لكلا الجنسين، واستخراج القيّم التائية المحسوبة باستخدام الاختبار التائي (T-test) لعينتين مستقلتين وأظهرت النتائج كما في الجدول

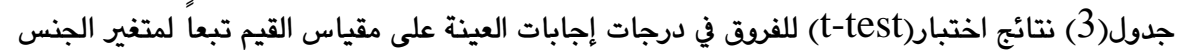

\begin{tabular}{|c|c|c|c|c|c|c|c|}
\hline الدلالة الإحصائية & قالجدولية & قالمحسوبة & درجة الحرية & الإنـراف & الحسابي & العدد & الجنس \\
\hline \multirow{2}{*}{ دالة عند مستوى } & \multirow{2}{*}{1.98} & \multirow{2}{*}{-2.42} & \multirow{2}{*}{120} & 13.54 & 71.17 & 63 & ذكر \\
\hline & & & & 15.02 & 77.44 & 59 & أنثى \\
\hline
\end{tabular}

الجنس والفروق لصالح الاناث في اتجاهاتهن السلبية نحو قيمة المال. يعزف الباحث ذلك إلى أن الأناث أكثر حاجة للمال لتلبية حاجاتهم

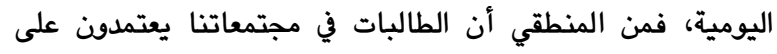

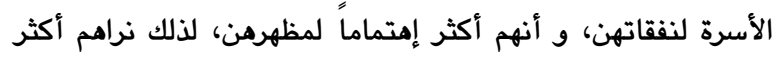

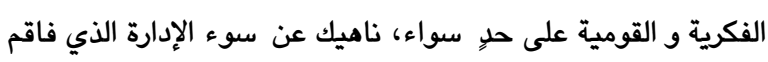
نسبة البطالة و التجويع و تدهور التعليم و الصحة، و تفكيك تما سك التك

أوضحت نتائج البحث إلى أن الوسط الحسابي لمجموع أفراد عينة

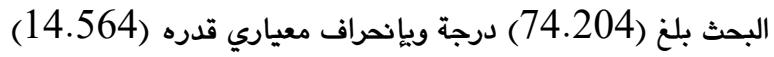

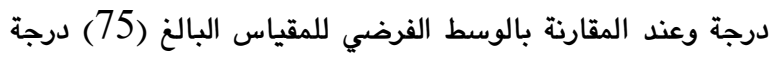

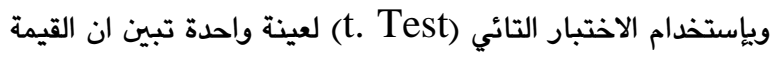

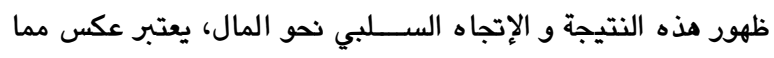

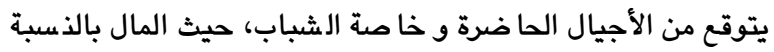

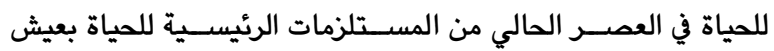
كريم، كما و خلاف ما يتوقع منهم في هذا المرحلة حيث بناء العائلة و مشاريع المستقبلية لديهم يتطلب المال. يعزى الباحث هذا الإتجاه

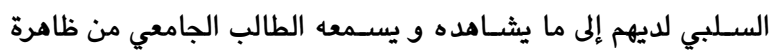
الفســاد المالي المتفشـــية في المجتمع و المؤدية إلى تفكيك القيم

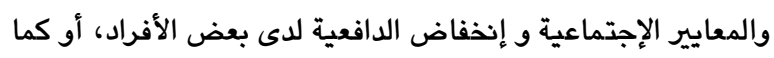

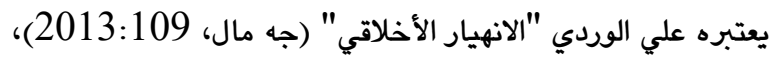
حيث لدى البعض ملايين الدولارات و الثروة خيالية، بينما عدد كثير

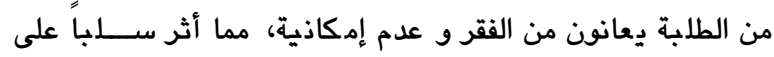

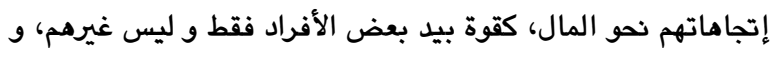
هذا الاتجاه السلبي انعكس في إجابات الطلبة. كانت لحروب المتتالية

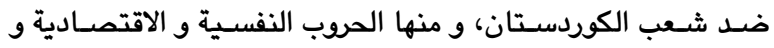
العسكرية في سنوات الأخيرة لها أثر في شعور طلبة عينة البحث بهذا

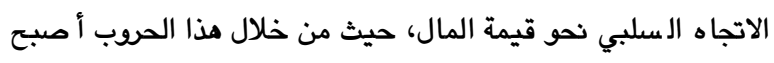

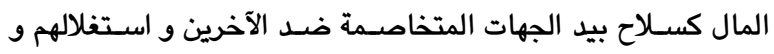

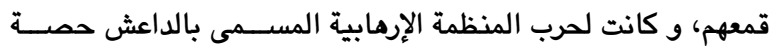

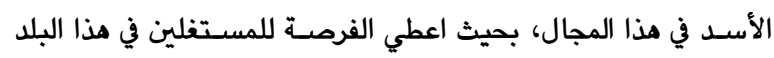

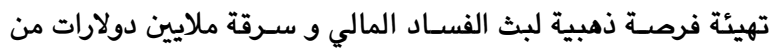
الرواتب المقطوعة من حكومة و اختلاسـها و تهريبها للخارج لشـراء الفيلات و الشقق و الترفيه و التبذير على حساب شعب كورد ستان

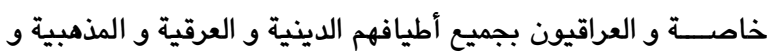
يتبين من الجدول(3) أن قيمة التائية المحسوبة بلغت (2.42) وهي أكبر من قيمة التائية الجدولية البالغة (1.98) عند مستوى الدلالة

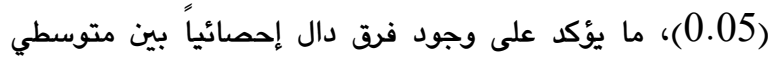
درجات العينة على مقياس التوجه نحو قيمة المال وفقاً لمتغير 


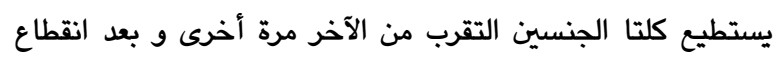

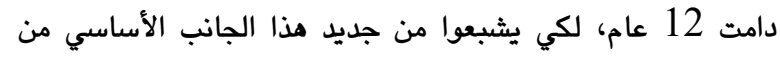

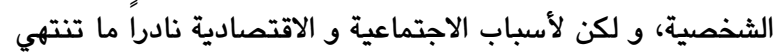

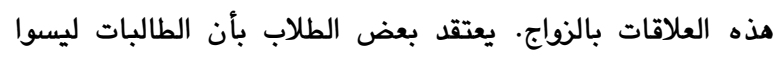

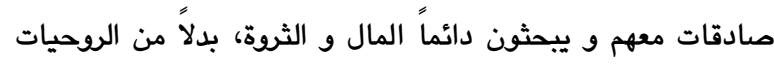
(جه مال، 2013: 96)، و لكن غالبية الطالبات يعتبرون هذا الانطباع غير صحيح. أي بمعنى آخر هن ضحيات التصورات الخاطئة

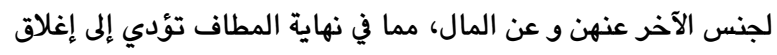

آفاق اختيار شريك الحياة في الجامعة و الزواج، و التخرج منها بيدٍٍ فارغة.

8-2-2-2- حالة الوالدين(عايش أو متوفي): لاختبار هذا الهدف تم استخدام اختبار (t-test) ذو الاتجاه الواحد،

وكانت النتيجة كالتالي كما مو موضح بالجدول(4):
حاجة للمال مقارنة بالطلاب، حيث يكونون أقل إهتماماً لمظهرهم حسب تقاليد الاجتماعية لمجتمعاتنا، و لكن عندما يرون نتيجة لإختلاف فاحش في مستوى الدخل بين عائلاتهم الغير قادرة على تلبية مثل هذه الحاجات الأساسية لهن يومياً، و بين الآخرين المتمكنين،

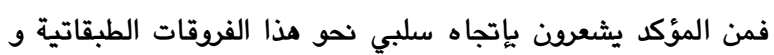
الاجتماعية و الاقتصادية، ما ينعكس في الجانب المادي و المالي. لأن مشاهدة ما يبذره البعض في الحياة قد يزداد أضعاف ما يحتاجهن لتلبية أبسط حاجاتهن الحياتية اليومية يدفعهم نحو الشعور بالغبن و الاضطهاد، كما و تشير مصادر و بحوث أن ليس مناك نموذج في كل العالم ما تعانيه المرأة في مجتمعاتنا، حيث ليس لهمومهم نهاية من الظلم و الأنى و الخوف منذ الصغر لحد الزواج وهي مضحية و محرومة من كل أنواع الرفاهية (ياسين، 2011، 301). كما و يعزف الباحث مذا الإتجاه السلبي لدى الطالبات إلى بعض العوامل العاطفية المرتبطة بفرص الزواج داخل المؤسسات التعليم العالي، و التي هي مكانة التي

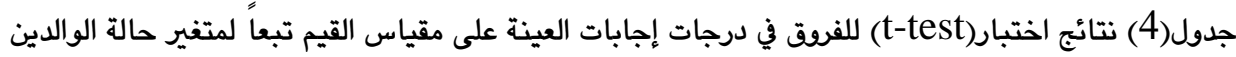

\begin{tabular}{|c|c|c|c|c|c|c|}
\hline مستوى الدلالة & قيمة ف الجدولية & قيمة ف المحسوية & درجات الحرية & متوسط المربعات & مجموع المربعات & مصدر التباين \\
\hline \multirow[t]{3}{*}{ غير دالة (0.05) } & \multirow[t]{3}{*}{4.78} & \multirow[t]{3}{*}{1.46} & 2 & 309.20 & 618.40 & بين المجموعات \\
\hline & & & 119 & 210.50 & 25049.46 & داخل المجموعات \\
\hline & & & 121 & & 25667.87 & الحلي \\
\hline
\end{tabular}

قيمة المال يوجد لدى الجميع أفراد العينة دون تأثير لهذا المتغير في مذا التوجه السلبي.

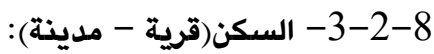
لاختبار هذا الهدف تم استخدام اختبار (t-test) ذو الاتجاه الواحد، لذلك تم استخراج المتوسط الحسابي والانحراف المعياري لعينة البحث

و كانت النتيجة كالتالي كما هو موضح بالجدول(5):

جدول(5) نتائج اختبار(t-test) للفروق في درجات إجابات العينة على مقياس القيم تبعاً لمتغير السكن

\begin{tabular}{|c|c|c|c|c|c|c|c|}
\hline الدلالة الإحصائية & قيمة ت الجدولية & قيمة ت المحسوبة & درجة الحرية & الإنـراف المعياري & المتوسط الحسابي & العدد & السكن \\
\hline \multirow{2}{*}{ غير دالّة (0.05) } & \multirow{2}{*}{1.186} & \multirow{2}{*}{0.037} & \multirow{2}{*}{120} & 15.09 & 74.86 & 22 & قرية \\
\hline & & & & 14.52 & 74.06 & 100 & مدينة \\
\hline
\end{tabular}

الذين يســكنون القرى ونظرائهم في المدن، حيث في عصــرنا الحالي هناك تشابه كبير في طريقة العيش بين الطلاب المدن والقرى. 8-2-2-4 المرحلة الدراسية: لاختبار مذا الهدف تم استخدام اختبار (t-test) ذو الاتجاه الواحد، وكانت النتيجة كالتالي كما مو موضح بالجدول(6): يتبين من الجدول(5) أن قيمة التائية المحســـوبة بلغت (0.037) وهي أصغر من قيمة الجدولية (1.65) عند مسـتوى (0.05) ، ما

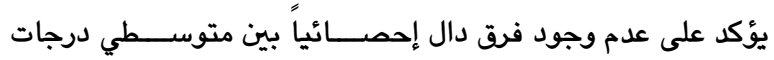
العينة على مقياس التوجه نحو قيمة المال وفقاً لمتغير الســــن. ويعزو الباحث هذا التشابه السلبي نحو المال في النتائج بين الطلاب جدول(6) نتائج اختبار(t-test) للفروق في درجات إجابات العينة على مقياس القيم تبعاً لمتغير المرحلة

\begin{tabular}{|c|c|c|c|c|c|c|c|}
\hline الدلالة الإحصائية & قيمة ت الجدولية & قيمة ت المحسوية & درجة الحرية & الإنـراف المعياري & المتوسط الحسابي & العدد العد & المرحلة \\
\hline \multirow{2}{*}{ غيردالة (0.05) } & \multirow{2}{*}{1.98} & \multirow{2}{*}{-1.16} & \multirow{2}{*}{120} & 14.71 & 71.31 & 76 & اولى \\
\hline & & & & 13.12 & 78.97 & 46 & ثانية \\
\hline
\end{tabular}


ظهور القيم السلبية الاجتماعية و السياسية والتربوية لدى أفراد

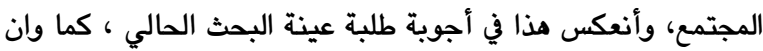

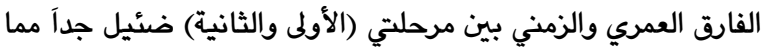
جعل نظرتهم إلى المال بنفس الطريقة.

8-2-5-2- المستوى التعليمي و الثقافي لوالدين الطلبة: وللتحقق من هذا الهدف و دلالة الفرق إحصائياً تم استخدام اختبار (ANOVA)

يتبين من الجدول(6) أن قيمة التائية المحسوية البالغة (1.16) وهي

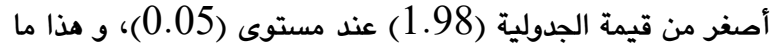
يشيرإلى عدم وجود فرق دال إحصائياً بين متوسطي درجات العينة

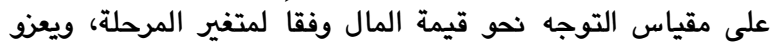

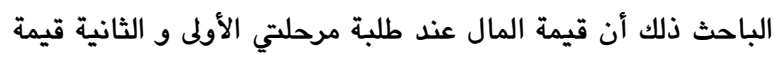
متشابهة، و جميع الطلبة ينظرون إليها من خلال رؤيتهم العامة

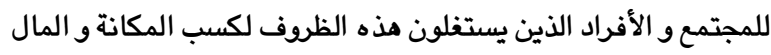

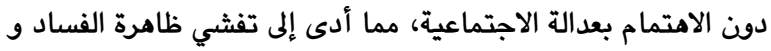

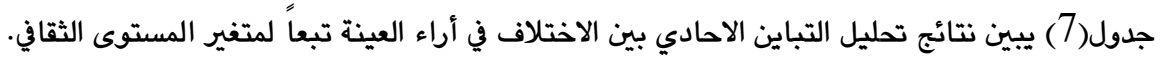

\begin{tabular}{|c|c|c|c|c|c|c|}
\hline مستوى الدلالة & قيمة ف الجدولية & ف المحسوبة & درجات الحرية & متوسط المربعات & مجموع المربعات & مصدر التباين \\
\hline \multirow{3}{*}{ غيردالة (0.05) } & \multirow[t]{3}{*}{3.94} & \multirow[t]{3}{*}{0.346} & 3 & 74.63 & 223.91 & بين المجموعات \\
\hline & & & 118 & 215.62 & 25443.96 & داخل المجموعات \\
\hline & & & & & 25667.87 & الكلى \\
\hline
\end{tabular}

بفقدانه القدرة على توكيد أية قيمة ايجابية والاعتقاد بأهميتها، قد يقوده إلى التخلي عن قيمه ومن ثم فقدان معنى وجوده في المجتمع و

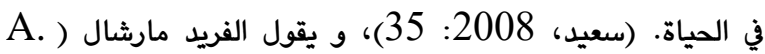
(Marshall

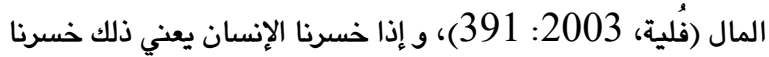

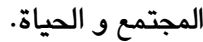
8-6-6 - - - - مهنة الأب:

لاختبار هذا الهدف تم استخدام اختبار (ANOVA)، وكانت

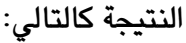

ويظهر من بيانات الجداول(7) عن عدم وجود فروق دالة إحصائياً في

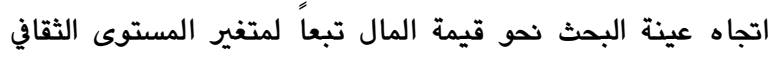
لوالدين الطلبة، لأن القيمة الفائية المحسوية البالغة(0.346) كانت أقل من القيمة الفائية الجدولية البالغة (3.94) عند مستوى الدلالة

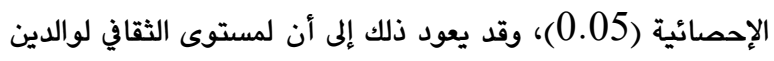
الطلبة ليس له تأثير في أتجاهات الطلبة عينة البحث نحو قيمة المال، وذلك جميع الأفراد من جميع مستويات الثقافية ينظرون إلى قيمة المال من خلال تقيمهم لما يحدث فيما حولهم من الحوادث الاقتصادية و الاجتماعية و السياسية. يقول رولو ماي أن الانسان المعاصر جدول(8) يبين نتائج تحليل التباين الاحادي بين الاختلاف في أراء العينة تبعاً لمتغير مهنة الأب.

\begin{tabular}{l|r|r|r|r|r|c}
\hline مئyyy \\
\hline
\end{tabular}

شرعية و على حساب الآخرين، مما ينعكس سلباً على توجه البعض، و منها طلبة عينة البحث الحالي نحو المال، و يعتبره مصدر معاناة لهم ولمجتمع نتيجة عدم وجود حدود لطموحات البعض الغير المشروعة واللامتناهية لجمع المال. 8-2-7-7 لمتغير مهنة الأم: لاختبارهذا الهدف تم استخدام اختبار (ANOVA)، وكانت

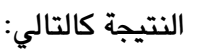

ويظهر من بيانات الجداول(9) عن عدم وجود فروق دالة إحصائياً في اتجاه عينة البحث نحو قيمة المال تبعا لمتغير مهنة الأب، لأن القيمة الفائية المحسوبة البالغة (0.467) كانت أقل من القيمة الفائية الجدولية البالغة (3.47) عند مستوى الدلالة الإحصائية (0.05)، وقد يعود ذلك إلى أن لمهنة الأب ليس لها تأثير في أتجاهات الطلبة السلبية نحو قيمة المال في المرحلة الراهنة المليئة بمشكلات المتعلقة بالمال، و طمع بعض الناس الانتهازيين للفرص في كسبها بطرق غير جدول(10) يبين نتائج تحليل التباين الاحادي بين الاختلاف في أراء العينة تبعاً لمتغير مهنة الأم. 


\begin{tabular}{|c|c|c|c|c|c|c|}
\hline مستوى الدلالة & قيمة ف الجدولية & ف المحسوبة & درجات الحرية & متوسط المربعات & مجموع المربعات & مصدر التباين \\
\hline \multirow[t]{3}{*}{ غيردالة (0.05) } & \multirow[t]{3}{*}{4.78} & \multirow[t]{3}{*}{0.351} & 75.257 & 2 & 150.514 & بين المجموعات \\
\hline & & & 214.432 & 119 & 25517.363 & داخل المجموعات \\
\hline & & & & 121 & 25667.877 & الكلي \\
\hline
\end{tabular}

وقد يعود ذلك إلى أن لمهنة الأم ليس لها تأثير في أتجاهات الطلبة

نحو قيمة المال.

8-8-8 المستوى الاقتصسادي:

لاختبار مذا الهدف تم استخدام اختبار (ANOVA)، وكانت
ويظهر من بيانات الجداول(10) عن عدم وجود فروق دالة إحصائيا في اتجاه عينة البحث نحو قيمة المال تبعاً لمتغير مهنة الأم، لأن القيمة الفائية المحسوية البالغة (0.351) كانت أقل من القيمة الفائية الجدولية البالغة (4.78) عند مستوى الدلالة الإحصائية (0.05)،

النتيجة كالتالي:

\begin{tabular}{|c|c|c|c|c|c|c|}
\hline مستوى الدلالة & قيمة ف الجدولية & ف قلمسموية & درجات الحرية & متوسط المربعات & مجموع المربعات & مصدر التباين \\
\hline \multirow{3}{*}{ غيردالة } & \multirow[t]{3}{*}{4.78} & \multirow[t]{3}{*}{0.455} & 2 & 97.48 & 194.96 & بين المجموعات \\
\hline & & & 119 & 214.05 & 25472.91 & اخل المجموعات \\
\hline & & & 121 & & 25667.87 & الكلى \\
\hline
\end{tabular}

الوقت الحالي وهذا يمكن تفسيره إلى أن الفارق المادي والاقتصادي بين عوائل الطلاب هذا القسم ليس بذلك الفارق الكبير مما أدى إلى نظرتهم نحو قيمة المال تكون متقاربة. 8-2-9-عدد أفراد الأسرة: لاختبار مذا الهدف تم استخدام اختبار (ANOVA)، وكانت

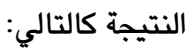

ويظهر من بيانات الجداول(11) عن عدم وجود فروق دالة إحصائيا

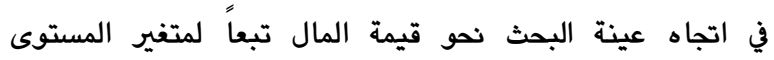
الاقتصادي لعائلة عينة البحث، لأن القيمة الفائية المحسوية البالغة (0.455) كانت أقل من القيمة الفائية الجدولية البالغة (4.78) عند مستوى الدلالة الإحصائية (0.05)، و يعزو الباحث ذلك إلى أن جميع الأفراد من جميع الطبقات الاقتصادية لمتغير المستوى الاقتصادي لعائلة الطلبة ليست لها علاقة بتوجههم نحو قيمة المال السلبية في

\begin{tabular}{|c|c|c|c|c|c|c|}
\hline مستوى الدلالة & قيمة ف الجدولية & ف قلمحسوية & درجات الحرية & متوسط المربعات & مجموع المربعات & مصدر التباين \\
\hline \multirow[t]{3}{*}{ غيردالة (0.05) } & \multirow[t]{3}{*}{3.94} & \multirow[t]{3}{*}{0.491} & 3 & 105.44 & 316.33 & بين المجموعات \\
\hline & & & 118 & 214.84 & 25351.54 & داخل المجموعات \\
\hline & & & 121 & & 25667.87 & الكلي \\
\hline
\end{tabular}

8-3-الهدف الثالث: التعرف على تسلسل المجالات لمقياس اتجاه عينة من طلبة الجامعة نحو قيمة المال. لاختبار هذا الهدف تم إستخراج حدة الفقرات حسب تكرارات إجابات عينة البحث وفقا لبدائل الخمسة لكل فقرة من فقرات الاستبيان، و من ثم ترتيب الفقرات حسب تكراراتها و درجاتها ترتيباً تنازلياً بالنسبة للفقرات الأخرى في الاستبيان، وأعتمد الباحث درجات المقياس المتدرج هي (4،5،3،2، 1,2)، أي أن الوسط المرجح يقع
ويظهر من بيانات الجدول (12) عن عدم وجود فروق دالة إحصائياً في اتجاه عينة البحث نحو قيمة المال تبعاً لمتغير عدد أفراد الأسرة لعينة البحث، لأن القيمة الفائية المحسوية البالغة (0.491) كانت أقل من القيمة الفائية الجدولية البالغة (3.94) عند مستوى الدلالة الإحصائية (0.05)، و يعزو الباحث ذلك إلى أن جميع الأفراد عينة البحث الحالي من جميع مستويات من حيث عدد الافراد و حجم الاسرى ينظرون بنفس التوجه نحو قيمة المال سواء كانت الاسرى 
بين (صفر و 5)، و اعتبار الفقرة ايجابية أم سلبية اعتماداً على مضمونها، و كانت النتيجة كما مو موضح بالجدول(13):

جدول(13) يبين نتائج الددة و تسلسل الفقرات حسب تكرارات إجابات عينة البحث وفقاً لبدائل الخمسة لكل فقرة من فقرات الاستبيان و بيان درجة الإتجاه لدى العينة نحو قيمة المال.

\begin{tabular}{|c|c|c|c|}
\hline تسلسل الفقرات & حدة الفقرات & 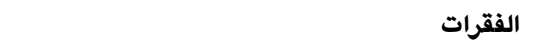 & ت. \\
\hline \multicolumn{4}{|c|}{ مجال الخير: } \\
\hline 10 & 3.270 & المال مهم جداً في حياتنا. & 1 \\
\hline 7 & 3.385 & المال خير. & 2 \\
\hline 8 & 3.295 & المال شيىء قَيِّم جداً. & 3 \\
\hline 2 & 3.614 & المال وسيلة لتحقيق فعل الخير. & 4 \\
\hline 23 & 2.565 & المال يستطيع شراء المتعة و الرفاهية. & 5 \\
\hline 17 & 3.024 & المال جذّاب. & 6 \\
\hline 25 & 2.098 & من المهم أن يدخر المال. & 7 \\
\hline \multicolumn{4}{|c|}{ مجال الشَّر: } \\
\hline 15 & 3.123 & المال هو أصل كل الشرود. & 8 \\
\hline 4 & 3.491 & المال سبب ضياع طيبة الانسان. & 9 \\
\hline 1 & 4.008 & المال لايجمع الّا عن طريق الحرام. & 10 \\
\hline 3 & 3.549 & المال يدفع مالكه نحو الرذائل. & 11 \\
\hline 11 & 3.245 & المال لا يُفيد الّا مالكه. & 12 \\
\hline 9 & 3.286 & المال الذي ندخره، هو المال الذي نكسبه. & 13 \\
\hline \multicolumn{4}{|c|}{ مجال الإنجاز: } \\
\hline 12 & 3.172 & المال يُعبر عن إنجازات الفرد. & 14 \\
\hline 6 & 3.434 & المال وسيلة لتحقيق الاهداف. & 15 \\
\hline 5 & 3.434 & المال يشتري كُل شيىء. & 16 \\
\hline \multicolumn{4}{|c|}{ مجال الاحترام و تقدير الذات: } \\
\hline 16 & 3.123 & المال يجعل الناس تحترمك. & 17 \\
\hline 20 & 2.713 & المال يمنحنا الشرف. & 18 \\
\hline 13 & 3.163 & المال يجلب لك كثيراً من الأصدقاء. & 19 \\
\hline \multicolumn{4}{|c|}{ مجال الميزانية: } \\
\hline 18 & 2.950 & أتعامل مع أموالي بحرص شديد. & 20 \\
\hline 24 & 2.098 & دائماً أضع لنفسي ميزانية مالية و بحذر شديد. & 21 \\
\hline \multicolumn{4}{|c|}{ 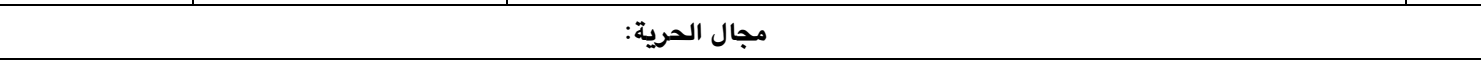 } \\
\hline 21 & 2.655 & المال يمنحك الاستقلالية و الحرية. & 22 \\
\hline 19 & 2.819 & عندما يكون معي كمية مناسبة من المال أشعر بالأمان. & 23 \\
\hline \multicolumn{4}{|c|}{ مجال القوة: } \\
\hline 22 & 2.582 & المال يمنحك الفرصة لتحقق كل ما ترغب فيه. & 24 \\
\hline 14 & 3.123 & المال يعني القوة. & 25 \\
\hline
\end{tabular}

3.491)، ولذلك حصلوا بالتوالي على التسلسل الأول، و الثاني، و الثالث، و الرابع. يرى علي الوردي أن المال لدى أهل المدن هو عصب المبل الحياة، وحبهم للمال مختلفة عن حب المال الموجود لدى البدووالذين ئرين لا يحبون المال لذاتها بل لكي يتكرموا بها على الناس، فينالوا المكانة
يظهر من بيانات جدول(13) أن قيمة الوسط المرجح لفقرات الأربعة، يعني بلغت على التوالي (المال لايجمع الّا عن طريق الحرام) و (المال وسيلة لتحقيق فعل الخير) و (المال يدفع مالكه نحو الرذائل) و (المال سبب ضياع طيبة الانسان) (4.008، 3.614، 3.549، 
أقوياء غير قادرون على مواجهة اكتساب الفقراء للمعرفة التي يصعب عليهم السيطرة عليها و هم أقل قوة في مواجهة هذه الحركة. لذلك مواءكي توصي هذه الدراسات بعدة خطوات لمواجهة مذه المخاطر و ملئ الفجوة بين التقدم و التخلف و بين الرفاهية و الفقر، و بخاصة عن

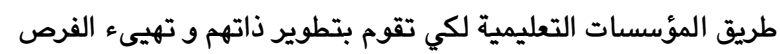

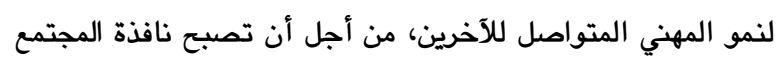
التي يطل منها على التقدم و يستشرف بها المستقبل، يعبر بها نحو

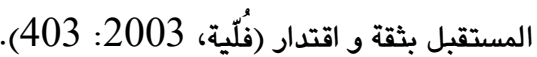
9- الإستنتاجات و التوصيات والمقترحات: وفي ضوء نتائج البحث تم التوصل إلى مجموعة من الإستنتاجات و التوصيات والمقترحات وكما يأتي:

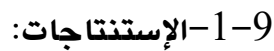
1. وجود اتجاه سلبي لدى طلبة عينة البحث الحالي نحو قيمة المال، أي أنهم يقيمون المال بمستوى واطىء بشئ بشكل عام. 2. أن طلبة عينة البحث تعتبر المال لايجمع إلّا عن طريق الحرام، كما و يرون المال وسيلة لتحقيق الخير وليس وسيلة لاستغلال الآخرين، لأنه يدفع مالكه نحو السلوك الرديء و الرذيلة، و ضياع

طيبته كإنسان. 3. يعتقدون طلبة عينة البحث بأن من المهم أن يدخر المال، بدلاً من حصوله بطرق غيرشرعية وغير قانونية كالاختلاس والفساد، و يون

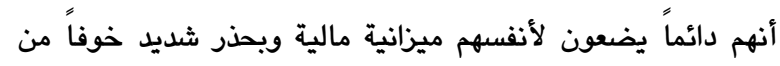
المفاجئات التي قد تؤدي إلى أزمات المالية في ظل الظروف السياسية والعدوان الاقليمي والعالمي ضد شعب كوردستان، كما و يرون الطلبة

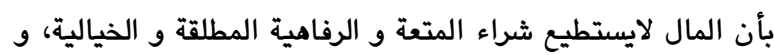

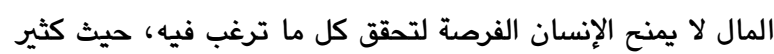
من الجوانب الروحية والمعنوية والإنسانية لايمكن شراءه بمجرد

4. أن عينة البحث يشعرون بغبن تجاه قيمة المال، حيث يعتبون

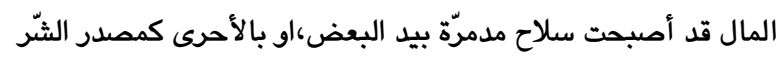
للآخرين و المجتمع، و مذا الاتجاه مبين من اجاباتهم لفقرات

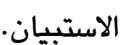
9-2-2 - 2- (التوصيات:

1. توجيه عمليتي التعليم والتعلم في الإقليم أن تكون أكثر

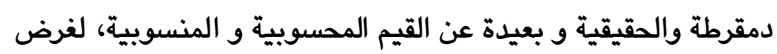

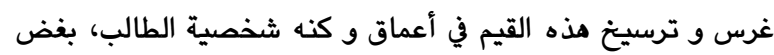
النظر عن توجهاته السياسية و معتقداته و ديانته و مذهبه و إنتمائه

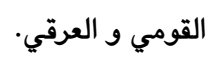

العالية والسمعة الحسنة بينهم. أن الناس في مجتمعاتنا يحترمون الغني و يتزلفون له، و لكن في نفس الوقت يحسدونهم، و يتحدثون في مجالسهم الخاصة عن الوسائل الدنيئة التي جمع بها ماله، لكنهم لا يكادون يرونه قادما حتى يقوموا له احتراماً و يوسعون له صدر المجلس(الوردي، 2013: 345). أن قيمة الوسط المرجح التي حصلوا كل من فقرات (من المهم أن يدخر المال) و (دائماً أضع لنفسي ميزانية مالية و بحذر شديد) و (المال يستطيع شراء المتعة و الرفاهية) و(المال يمنحك الفرصة لتحقق كل ما ترغب فيه) على

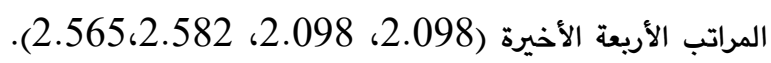
يمكن القول إن احترام الأغنياء في مجتمعاتنا جعل الناس يتكالبون على جمع المال بكل السبل، و لا ييالون أن تكون مشروعة أو غير

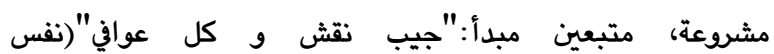
المصدر:346)، قد يعزى الباحث هذا الاتجاه السلبي نحو المال جزء

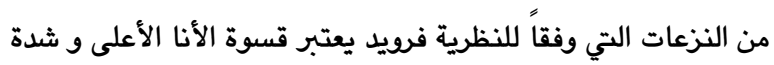
صرامتها تحيل الشخص نحو شعور بالذنب تجاه المال، مما يدفع

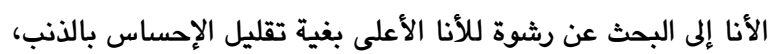
فتنكر الأنا كل مصادر القوة المتمثلة في قيمة المال، كمحاولة لاستمالة الأنا الأعلى. كما و أن لعامل القيم والاتجاهات النفسية

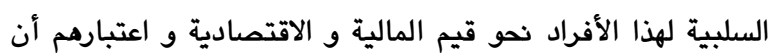
المال هو أصل كل الشرود والأزمات، دود حاسم في ظهور ما يسمى فوبيا المال لدى البعض، مما تحثهم دوافع لاشعورية نحو سلوك

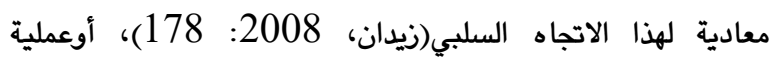
الاستبدال أو التبرير كجزء من الحيل النفسية التي يحافظه الفرد من الفناه الشعور بالاثم أو الفشل في الحصول على غرض معين، و إرضائه الرمزي كبديل عن حاجات و أهداف أخرى لايستطيع الفرد الحصول عليها بالوسائل الطبيعية (كمال، 1988 : 66)، لأن المال هو الوحيد الذي لاينافس بل القادر على اقتلاع أي هوية أو فكرة من أي رأس بشري (حمادي، 2007 : 136). تشير دراسات حديثة إلى تنبيه في القرن الحالي من صراعات و صدام الحضارات التي ستقام من جراء تغيرات جوهرية و منها القيم و الثقافات و الأفكار، مما يؤدي تحولاً أساسياً في الشئون الإنسانية. أن منطقتنا في المستقبل ستواجه استمرار الصراعات و إحساس بالغبن و الهزيمة، زيادة التخوف منها، و خاصة الدول النامية، من ازدياد الفجوة بين الأغنياء و الفقراء، و هذا طبيعي عندما عرفنا جذور هذا العنف له علاقة وحه

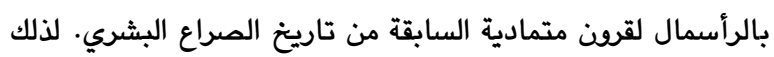
نرى أنه الفقراء و الضعفاء يحاولون اكتساب المعرفة و إيداعها ليستخدمها ضد الأغنياء، و حسب الدراسات المذكورة أن هذا سيكون محور الأساسي لصراعات المستقبل، و لذلك نرى، بالمقابل، 
القهري و الإسراف القهري، و ظهور مظاهر و مشاعر مرضية مختلفة لديهر. كلها متغيرات قائمة على قيم التراخي و الإعتمادية و قانون

5. ضرورة توعية الطلبة أن المال غاية و ليس وسيلة، و صحيح أنه قد يمثل قيمة مهمة في حياتهم النفسية و الاجتماعية، لكنه لايمثل القيمة العليا التي تعِّول عليها في كل أفعالهم و سلوكياتهم. قد يكون الخبرة النفسية التي يخلقها المال ليست خبرة سارة، و إنما خبرة مملوءة بالألم و الاضطراب و المرض و المعاناة من كثير من المشكلات

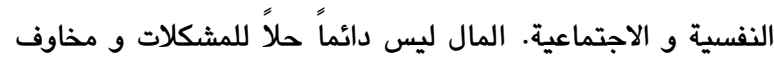
الإنسان، بل كثيراً ما يصنعهم. 6. توفير فرص التعيين و العمل في القطاع الحكومي و الدوائر لخريجي الكليات و المعاهد لممارسة مهنة و الشعور بالطمائنينة و الأمن المالي و الاقتصادي أكثر و السد من جوعهم الاقتصادي و المعنوي و العاطفي في ظل الفقر أو البطالة، و تقليل من الكراهية و الغبن لديهم نحو الآخرين المتمكنين و طبقات اقتصادية العالية، و التي قد تسبب التعصب و الانفعال و التمرّد و الإنحراف و التجاء إلى ولى المنظمات الإرمابية و المخرّة في المستقبل لغرض الثأر و الانتقام و

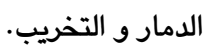
7. حملة وطنية من قبل الأغنياء و الأشخاص المتمكنين لبناء و و إنشاء المعامل الإنتاجية و الورثات المهنية في المنطقة الغنية بالبساتين و الزراعة و المياه و المعادن الطبيعية بالتنسيق مع الجهات

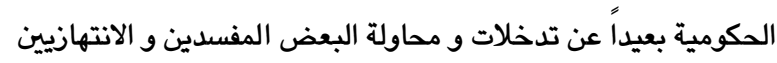
لعرقلة العملية و لغرض الاستفادة و اكتساب سهام خاص في هذا

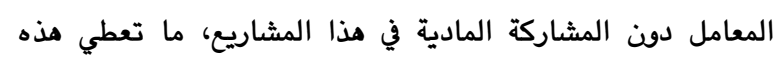
المشاريع في القطاع الخاص فرصة لآلآف المتخرجين من جامعة زاخو و المدارس الإعدادية المهنية في المدينة، و بذلك الإحساس بدورهم و

شخصياتهم، و تعديل هذه الاتجاه السلبية نحو المال لديهم. 8. بث ثقافة فهم السعادة و الاحساس بها، حيث أن السعادة عملية دينامية وظيفية، لايمكن أن تتوقف على عنصر واحد فقط و هو المال، بل هي مزيج من عناصر نفسية اجتماعية تتفاعل معاً حتى ونى

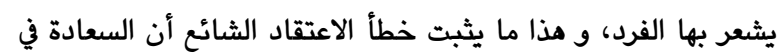

قيمة المال و الثروة فقط.

9. التركيز على مناهج التعليم في المؤسسات التعليمية كوسيلة الرئيسية لمواجهة التطرف في حب المال و الثروة، بالإعتماد على أساليب المنهجية و عقلانية في هذا الاتجاه حيث تتناول أسباب التطرف في حب المال ، و أخطاره و أضراره التربوية والإجتماعية و

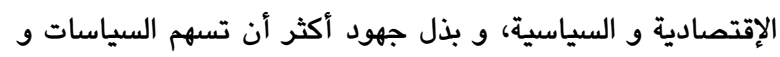

2. ضرورة اتخاذ تدابير و علاج جذري لإطاحة ظاهرة الفساد المالي و الإداري في أجهزة و المؤسسات الحكومية و القطاع الخاص، و التي أدت إلى ظهور قيم غير مقبولة اجتماعيا المعتمدة على جمع المال على حساب الآخرين و خاصة شريحة الشباب، حيث تفثي البطالة و حصر المال بيد عدد محدد من الأفراد، و ظهود اختلاف فاحش بين الطبقات، مما أدى إلى اليأس و التشاؤم لدى الطلبة و الشباب من الحياة، و توجه سلبي نحو المال التي برأيهم جُمعت بين أيادي طبقة خاصة انتهازية، برغم من وجود هيئة النزاهة ولكن لحد الآن لا يزال يشاهد الفساد في المجتمع و بعض الأفراد المستغلين

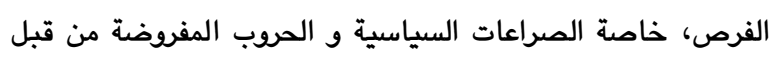
منظمات الإرهابية و الدول المجاورة لجمع المال أكثر، دون مراعاة روحية مئات الشباب الذين لم تستطيع الحصول على قدر من المال لبناء حياتهم العائلية و الإحساس بكيانهم و شخصياتهم. يتطلب ذلك تأهيل المجتمع نحو قيم انسانية و الحضارية لتخدم هدف الحياة و المجتمع، و ذلك عن طريق تنشئة مواطنين يقظين مسؤولين و منفتحين على الآخرين، يقدرون حقهم في الحياة و التمتع بها، و رفض كل أنواع الاستغلال و الاستبداد و الدكتاتورية في مختلف مناحي الحياة، و مجرد التفكير في المصالح الشخصية. 3. ضرورة الأخذ بنظر الإعتبار هذه الرؤية و الإتجاه الإيجابي للطلبة نحو قيمة المال من قبل التدريسيين و رئاسة القسم، دافعاً قوياً لأنفسهم من خلال تشجيع الطلبة و استغلال طاقاتهم واتجاهاتهم في سبيل رفع مستواهم العلمي بشتى أنواع الأساليب و الوسائل التعليمية، منها تدريس المواد و مساعدتهم كتابة التقارير و بحوث التخرج باللغة الكوردية بدلاً من اللغات الأخرى، حيث يجيد الطلبة مدئ اللغة الكوردية.

4. ينبغي أن تكون مناك فلسفة حياتية و تربوية شفافة و إنسانية في المؤسسات التربوية و التعليمية، لدى الطلبة نحو قيمة المال و

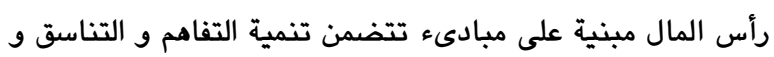
التسامح و الصداقة و الشعور بالمسؤلية تجاه المجتمع المحلي و و

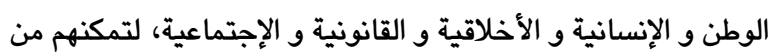
استغلال طاقاتهم و قدراتهم لحصول على عمل و مهنة و مال لازم للعيش و الحياة، و لتلبية حاجاتهم الحياتية بطرق صحيحة و قانونية و اقتصادية بعيدة عن الفساد المالي و الطموحات اللامتناهية الزائفة على حساب الآخرين و انتشال القيم اللاجتماعية و الحصول على ولى ولى مكاسب و مناصب على أساس المحسوبية و غيرها من طرق غير

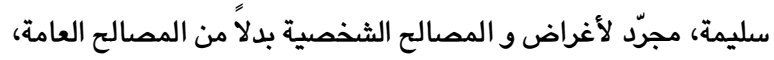

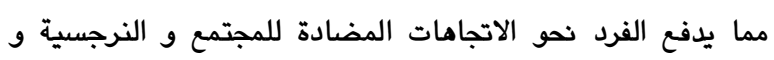
الأنانية، تبدو آثارها في الرشوة و البخل و النصب و الاحتيال و الادخار 
انجهام، بربرة (2010): الاقتصاد و التنمية، ترجمة: حاتم حميد

حسين،ط.1. دار كيوان للطباعة و النشر و التوزيع، دمشق.

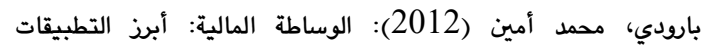

المعاصرة، ط.11، دار النور، سورية، لبنان، الكويت.

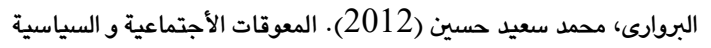

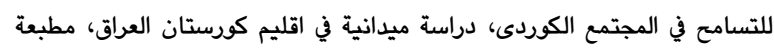

هاوار، دهوك، كردستان.(اطروحة دكتوراه المنشورة).

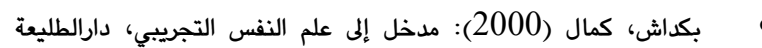

للطباعة و النشر، بيروت.

بكر، جوان اسماعيل (2013): جودة الحياة و علاقتها بالانتماء و القبول

الاجتماعيين، ط. 1، دار الحامد، عمان: الاردن(اطروحة دكتوراه منشورة).

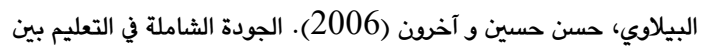

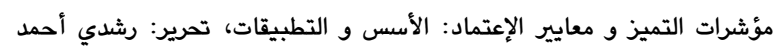
طعيمة، دار المسيرة للنشر، عمان:الأردن.

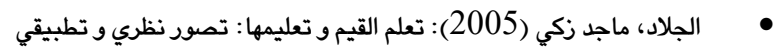
لطرائق و استراتيجيات تدريس القيم، ط.1. لدار، دار المسيرة للنشر و التوزيع، عمان.

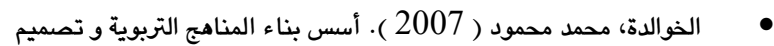
الكتاب التعليمي ، ط. 2، دار المسيرة، عمان: الأردن.

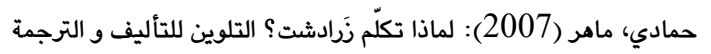

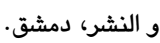
• زيدان، أكرم (2008): سيكولوجية المال:هراس الثراء و أمراض الثروة،

سلسلة عالم المعرفة (351)، الكويت. • سعيد، سعاد جبر (2008): القيم العالمية و أثرها في السلوك الإنساني، ط.1. عالم الكتب الحديث و جدارا لكتاب العالمي، عمان.

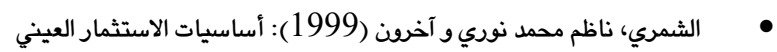
و المالي، ط.1. ، دار وائل للطباعة و النشر، عمان. • صالح، قاسم حسين (2011): الشخصية العراقية: المظهر و الجوهر، ط.2. طفاف للطباعة و النشر، لندن.

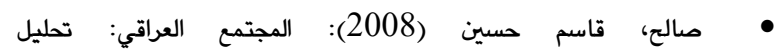
سيكوسوسيولوجي لما حدث و يحدث، ط.1. الدار العربية للعلوم ناشرون، بيوت.

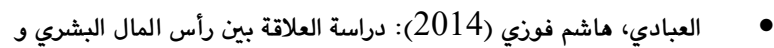

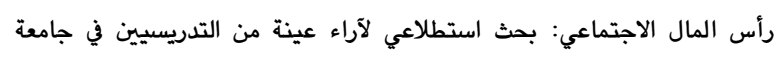

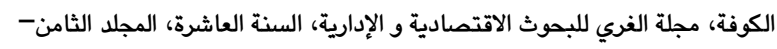

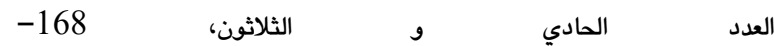
Hashimf2000@yahoo.com,

www.dr-). 193

(alabadi.com

عبدالحي، وليد (2007): مناهج الدراسات المستقبلية و تطبيقاتها في العالم العربي، مركز الإمارات للدراسات و البحوث الاستراتيجية، ط. 1. أبو أبو ظبي.

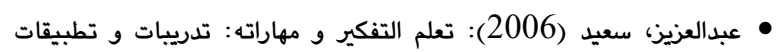
عملية، ط.1، دارالثقافة، عمان:الأردن. العثمان، ابراهيم بن عبدالله (2011): بناء و تعديل سلوك الأطفال، ط.

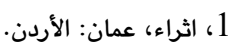
• العزي، صلاح حسن (2011): دود التنشئة الاجتماعية في الحد من السلوك الإجرامى، ط. 1، دار غيداء، عمان: الاردن.
البرامج التعليمية في تعزيز العدالة و المساواة في الحقوق و الواجبات لدى الطلبة و بناء شخصيته كمواطن صالح و أمين للدولة و المجتمع. 10. تحديد يوم للنضال ضد ظاهرة الفساد و حب المال المتطرف.

$$
\text { 9-3-المقترحات: }
$$

استكمالاً للفوائد المتوخاة من البحث نقترح:إجراء دراسة مماثلة عن إتجاه طلاب أقسام و كليات أخرى في الجامعة و جامعات إقليم كوردستان نحو قيمة المال ومقارنة نتائجها مع نتائج البحث الحالي، كما و ربطه ببعض المتغيرات الأخرى غير مشمولة بالبحث الحالي و منهم الإتجاه نحو الفساد المالي و الإداري.

المصادر باللغة الكوردية:

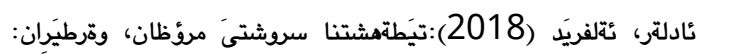

سيف الله علي مايى و سيار تمر صديق، ض. 1، ضاثخانا هيظى، دهؤك.

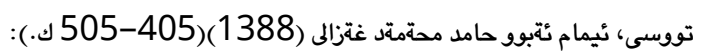

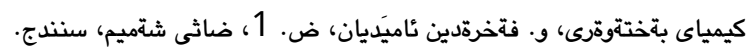

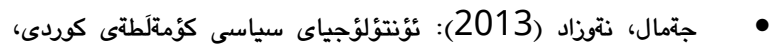
وةزارةتى ئشنبيرى و لاوان، هةوليَر.

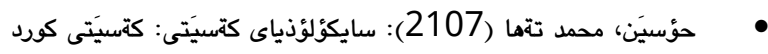

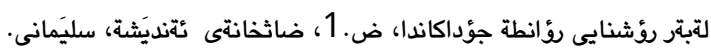

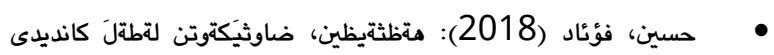

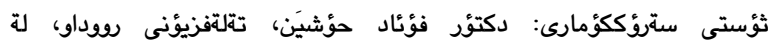

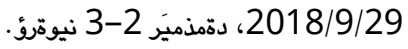

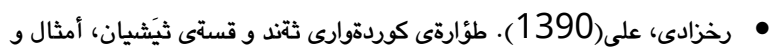
حكم كردى،ض.3، انتشارات كردستان، سنندج: ايران.

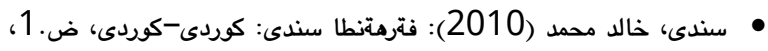
ضاثخانا هةوار. قة قةرضةتانى، كةريم شةريف (2009):سايكؤلؤذياى طةشة: مندالَ و مةرزةكار، ض. 1، ضاثخانةى ثةتيوةند، سليَمانى.

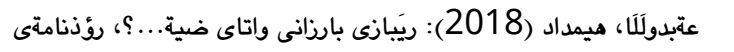

خَبات، ذ.5473، لة 2018/3/25، ل.6.

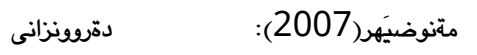

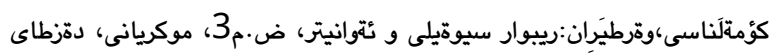
نأناراس،هةوليَر. ياسين، باقر (2011): كةسيتى تاكى عيَراقى، و. سةباح نيسماعيل، ض. 1، ضاثخانةى ناراس، هةوليَر.

المصادر باللغة العربية: - الماكية • ابراهيم، ماجد موريس (2005): الإرهاب الظاهرة و أبعادها النفسية، ط. (1) (1). دار الفارابي، بيروت، لبنان.

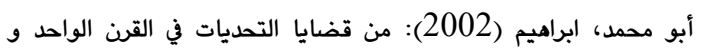

العشرين: التعليم في ضوء فكر النورسي، ط.1، شركة سوزلر للنشر، القاهرة.

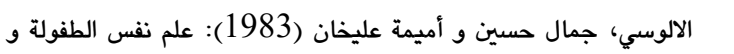

المراهقة، مطبعة جامعة بغداد. 
- $\quad$ Dunn, Dana S. (2001): Statistics and data analysis for the behavioral sciences. McGraw-Hill.

- Hair, Joseph F, et al (2006): Marketing research: with a changing information environment, $3^{\text {rd }}$ ed., McGraw-Hill, Irwin.

- Hakim, Albert B. (2006): Historical introduction to philosophy, $5^{\text {th }}$ ed., Prewtice Hall, USA. $\square$

- Jager, Ronald (1972): the development of Bertrand Russell's philosophy, $1^{\text {st }}$ pub., Humanities press.

- Inglehart, Ronald (2003): International studies in social, Islam, gender, culture, and democracy, findings from the world wide values survey and European value survey, De sitter pub. Valuom 4.

- Ingelhart, Ronald and Miguel Bazanez, Alejandro Moreno (2008): Human values and beliefs: A Grosscultural source, political, religious, sexual and economic norms in 43 societies. USA.

- Jones, Gareth R. , and George, Jenifer M. (2006): Contemporary management, $4^{\text {th }}$ ed. McGraw-Hill, Irwin.

- $\quad$ Kirk, Gwyn and Okazawa-Ray, Margo (2004). Women's lives: multicultural perspectives, $3^{\text {rd }}$ ed., McGraw-Hill, Higher education.

- $\quad$ Myers, Daivid G. (2005): Social psychology, $8^{\text {th }}$ ed., McGraw Hill, NY.

- Macionis, John J. (2005): Society the basics, $8^{\text {th }}$ ed, Pearson Prentice Hall. $]$

- Nelson, Jack L., et al (2007). Critical issues in education dialogues and dialectics, 6th ed., McGrawHill. $\square$

- Norris, Pippa and, Ronald Ingelhart(2007): Scared and secular religion and politics worthwilde, Cambridge University press. USA.

- Perrault, William D. et al (2008): essentials of marketing: A marketing strategy planning, McGrawHill-Irwin. $]$

- Rokeach M. (1979): Understanding human values. The free press, NY.

- West, Richard and Turner, Lynn H. (2004). Introducing communication theory, $2^{\text {nd }}$ ed. , McGraw Hill, NY.

- $\quad$ Winerman, Lea (2009): A Healthy mind, a long life, $21^{\text {st }}$ ed, annual edition, McGraw-Hill. $\square$

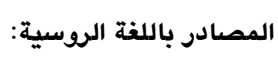

- Евсецова, Е. А.(2008): Аксиологический подход в обучении студентов истории педагогиеи, Педагогическое образование наука, но. 9, 12-15 с.

- $\quad$ Гаврилова, Е. В. (2003): Субъктивная

категоризация в межличностно и познании ценностные ориентаци и личности, Дисс. Ка. Психо.Наук. Кубангос. Униве. Краснадар, 24c.

- Леденоц, Д. С. (2007):Ценности как фактор смысльжизненых ориентацы соверменного руссиского студентов и их динамика напремер технических вузов горад Иркутска, дисс. Социо. Иркутска.

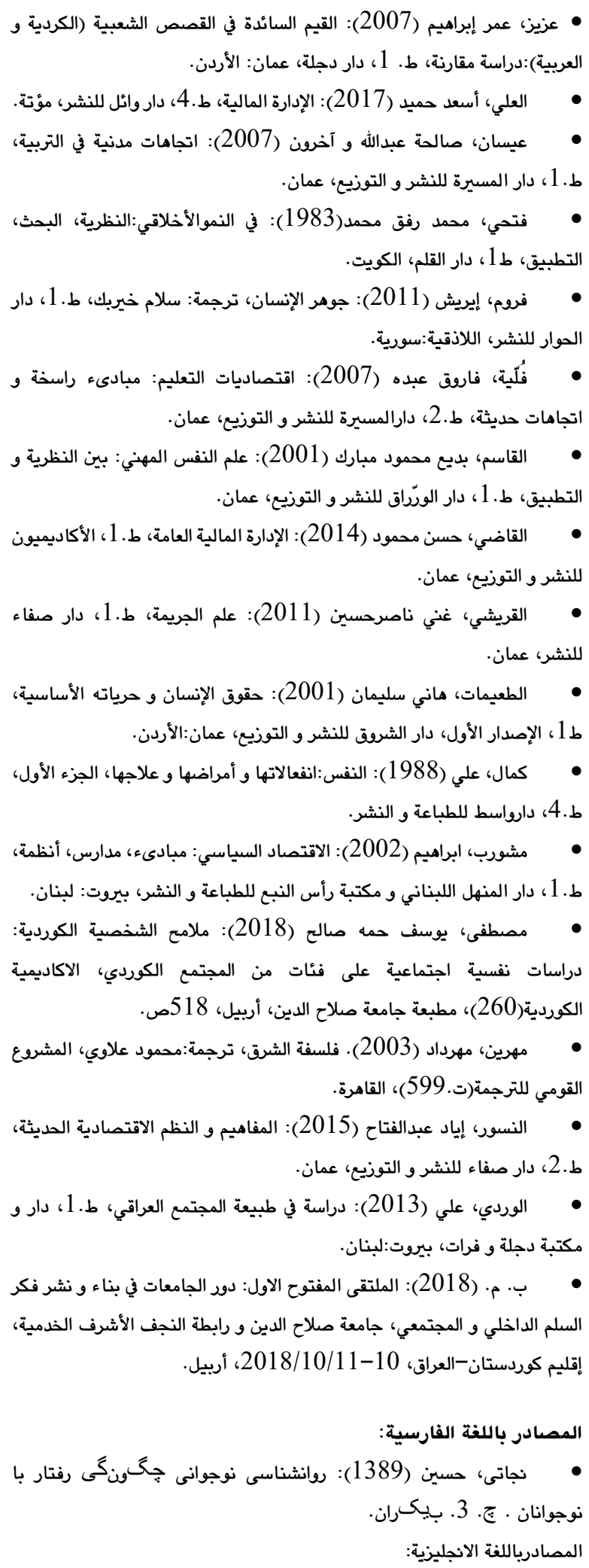

- Astington, Janet W., Paul L. Harris and Olson, David R. (1990): developing theories of mind.

- Colman, M. Andrew (2009): Oxford Dictionary of Psychology, $3^{\text {rd }}$ ed. Oxford university press، USA. 


\section{الملحق}

الملحق (1) أسماء المحكمين الذين تم الإستعانة بخبراتهم في صدق الترجمة (من العربية إلى اللغة الكوردية و العكس)

\begin{tabular}{|c|c|c|c|}
\hline الجامعة و الفاكولتي & التخصص & الاسم والمرتبة العلمية & $ت$ \\
\hline جامعة زاخو / التربية & طرق تدريس/اللغة الكوردية & م·م. عبدالستار حميد محمد & 1 \\
\hline جامعة زاخو / التربية & علم النفس التربوي & م· م. هيفاء وحيد محمد & 2 \\
\hline جامعة زاخو / التربية & مساعد باحث/ اللغة الكوردية & دلمان خالد يوسف & 3 \\
\hline جامعة زاخو / التربية & مساعد باحث- علم النفس & سَنَر داود حنا & 4 \\
\hline
\end{tabular}

(2):أسماء الخبراء و المحكمين الذين ثم الإستعانة بخبراتهم في صدق المقياس

\begin{tabular}{|c|c|c|c|}
\hline الاختصاص & مكان العمل & الاسم الثلاثي & 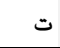 \\
\hline إدارة الأعمال & جامعة زاخو & أ.م. د. رنج محمد نوري & 1 \\
\hline طرق التدريس/التاريخ & جامعة زاخو & أ.م. د. ستار جبار حاجي & 2 \\
\hline الإدارة الإستراتيجية & جامعة زاخو & أ. م. د. ميهفان شريف كولي & 3 \\
\hline طرق تدريس الرياضيات & جامعة زاخو & أ.م. د. أزمار علي حسين & 4 \\
\hline علم النفس التربوي & جامعة زاخو & م. د. خلود بشير عبدالأحد & 5 \\
\hline علم النفس النمو & جامعة زاخو & م. د. زاهد سامي محمد & 6 \\
\hline الصحة النفسية & جامعة زاخو & م.د. نزار عصمت علي & 7 \\
\hline تخطيط تربوي & جامعة زاخو & م· بيوار طه شكري & 8 \\
\hline إدارة الأعمال & جامعة زاخو & م. م. دلشاد حبيب جبار & 9 \\
\hline القياس و التقويم & جامعة زاخو & م· م. فمان أحمد محمد & 10 \\
\hline إدارة الأعمال & جامعة زاخو & م·م. نزار محمد علي & 11 \\
\hline
\end{tabular}


Attitudes of a sample of students of college of administration and economic toward value of capital and its relationship with some variables

Nasraddin E. Mohammad

\section{Abstract: $:$}

The aim of study is to testify the statistical hypotheses concerning the significant differences between attitudes of a sample of students of college of administration and economic in Zakho University toward value of capital according to the variables of the study. The sample of the research consists of (122) students, which have been selected randomly from population (\%74). The researcher used a prepared questionnaire by (Zeydan, 2008) include of (30) items. The results of the research showed that members of research's sample have very high significant meaningful negative attitudes toward value of capital; also statistical significant differences among them according to the variable of gender, but there are no statistical significant differences among them according to the other variables of the study.

Keywords: Attitude, University students, Value, Capital.

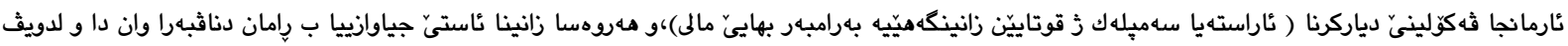

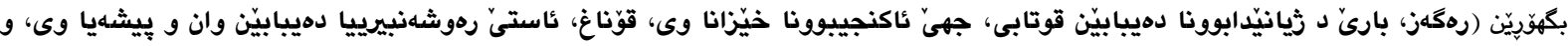

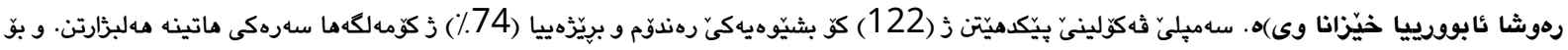

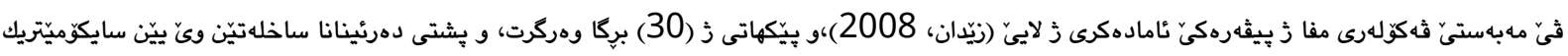

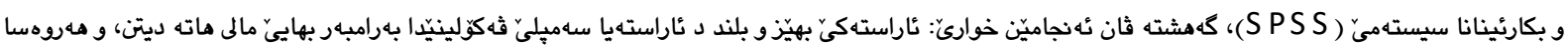

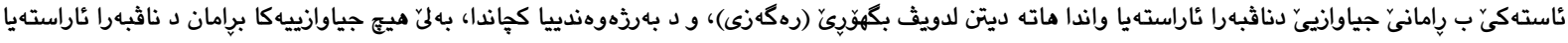

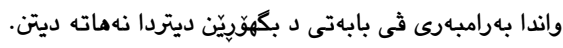

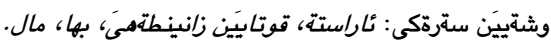

